\title{
MINERAL SURFACES AND THEIR IMPLICATIONS FOR MICROBIAL ATTACHMENT: RESULTS FROM MONTE CARLO SIMULATIONS AND DIRECT SURFACE OBSERVATIONS
}

\author{
A. LÜTTGE***, L. ZHANG* and K. H. NEALSON***
}

\begin{abstract}
Our recognition of the crucial role that microorganisms play in a large variety of water-rock interactions at earth surface conditions requires an improved understanding and experimental quantification of the biotically modified or controlled processes. As a consequence, a combination of modeling techniques, experimental and field observations are developing into a promising strategy to approach this difficult task.

This paper seeks to highlight some interesting questions and problems of microbial participation in mineral-water interactions and to present a modeling strategy that may help to study this exciting topic. Out of a voluminous body of work whose diversity of results underscores the complexity in the study of microbe-mineral interactions, we have chosen and briefly reviewed three recent experimental studies that have explored different aspects of the interaction between microbes and mineral surfaces. In the second part of this paper, we introduce a complementary approach that uses parameterized Monte Carlo simulations to explore and quantify crystal dissolution kinetics. This tool has already yielded considerable success in delineating abiotic water-mineral interactions, and we demonstrate here how it can be extended to the study of microbe-water-rock interactions. Finally, we discuss possibilities as to how this approach could be improved and simulation predictions tested in future laboratory work.
\end{abstract}

INTRODUCTION AND REVIEW OF SELECTED PAPERS

During the last decade, profound and fundamental changes have occurred in the way that many geologists, geochemists, and biologists view low temperature geochemistry. At the urging of geochemists such as Berner (Berner and Westrich, 1985; Berner, 1992, 2003; and Berner and Berner, 1995) and Helgeson (Helgeson and Amend, 1994), and others (for example, Amend and Helgeson, 2000; Royer and others, 2001), we have increasingly moved towards the view that interdisciplinary approaches including geology, biology, organic chemistry, and geochemistry will be needed to understand the complex phenomena that define the history and present day geology of the Earth (for an excellent overview see articles in Banfield and Nealson, 1997, and references therein). Thus, processes such as mineral formation, mineral dissolution, corrosion, and weathering, which were classically looked upon as "disciplinary" with most attention being focused on the abiotic issues (for a comprehensive overview see White and Brantley, 1995), have begun to slowly yield to more interdisciplinary approaches in which chemical processes, catalyzed by microbes are recognized as major players (see for example, Westbroek, 1991; Banfield and Hamers, 1997; Brantley and others, 2004). That is, in the areas of petrology and geochemistry, we have moved from a focus on the rock itself to one that must consider the activities that occur at the "bug-rock interface".

In modern societies, problems of water and soil pollution, loss of soil, secure strategies of waste deposition, remediation of contaminated sites, and the increasing threat of climate change have forced large parts of the scientific community to refocus and develop new strategies in their research. One of the results was the new interdisci-

\footnotetext{
*Department of Earth Science and Department of Chemistry, Rice University, 6100 Main Street, Houston, Texas 77005; aluttge@mail.rice.edu

**Center for Biological and Environmental Nanotechnology, Rice University, Houston, Texas 77005

***Department of Earth Sciences, University of Southern California, 223 Science Hall, 3651 Trousdale Parkway, Los Angeles, California 90089
} 
plinary approach mentioned above. The success of this approach is documented in the ever-increasing number of observations and data that provide evidence of rapid progress in our understanding of the importance of microbial interaction in geologic systems (for an overview, see Banfield and Nealson, 1997; Warren, 2004, and contributions therein). Virtually all interactions between organisms and minerals begin at the mineral surface. The study of these interactions in aqueous environments must by necessity involve an understanding of how microorganisms alter the physics and chemistry of contact between mineral and aqueous solution. Consequently, this alteration will change the kinetics of mineral dissolution and growth.

Our present study is directed towards this task. In the following, we review three recent experimental studies that have investigated different aspects of microbemineral interactions: surface recognition, attachment and interaction with the mineral surface. Based on the results of the direct experimental observations we then introduce a stochastic modeling approach using parameterized Monte Carlo techniques to explore effects of microbial alteration on mineral dissolution kinetics.

In general, one can look at the mineral world with regard to two major processes: mineralization and dissolution. In principle, and in fact, both processes occur abiotically and biotically, but the rates in the presence of the proper biotic catalysis can be orders of magnitude faster than the abiotic rates (for example, Barker and others, 1998). While both processes are of great interest and importance (for example, see Dove and others, 2003), we have focused our efforts to this point on the dissolution side (that is, the corrosion of metals and metal oxides, and the dissolution of minerals in the presence and absence of microorganisms). The work includes both experimental measurements as well as modeling approaches using Monte Carlo simulations, with the goal of understanding the quantitative importance of the biotic influences, as well as the qualitative differences that occur-observations that might provide clues to similar processes that have occurred in the geological past. This focus is in no way intended as a ranking of approaches; complementary modeling strategies such as molecular dynamics calculations and quantum mechanical approaches are equally important and have produced valuable results. Some of these results are reported in the present volume with an emphasis on metal adsorption on outer cell membranes (for example, Fein, 2000; Frost and others, 2003; Borrok and Fein, 2004; Borrok and others, 2004). Finally, model predictions need to be tested both experimentally and through field studies, and we therefore advocate a combination of modeling and experimental efforts.

It is well known that naturally occurring rocks, minerals, and glasses, as well as man-made materials such as ceramics and metal products, contain significant amounts of components that can be utilized as nutrients by (micro-) organisms (Lovley and Phillips, 1988; Rogers and others, 1998; Lovley, 2000) and plants (for example, Berner, 1992). Common examples are phosphate and metal oxides. During the "mining" of this vast source of nutrients from rocks and minerals, microbes often extract these molecules from the bulk solid structure. As a result of this action they destroy the mineral, glass, or metal in its existing form and mobilize the components (for example, Leyval and Berthelin, 1991; and Hinsinger and others, 1992). This biological activity has the potential to change or even completely override the abiotically controlled kinetics and cause significantly enhanced mineral dissolution and metal corrosion rates (for example, Barker and others, 1997, and references therein; Lüttge and Conrad, 2004; and Davis and others, 2004).

\section{Microbial Attachment}

One assumption has been that an important aspect of the participation of microbes in mineral-fluid interactions is the attachment of microbes at the surface. Much research has been conducted with respect to both the microbiology and 
geochemistry of the attachment problem, although only a few studies, however, have focused on the direct participation and quantification of microbes in mineral-water interactions. Therefore, while increasing (see for example, Kendall and Hochella, 2003), our knowledge is still limited and often speculative. An important prerequisite for major progress in this matter is insight into questions of surface recognition and attachment of microbes. How does a microbe recognize a crystalline surface that is characterized not only by its chemical composition but also by microtopography, different energetic sites, and heterogeneous composition? What factors conspire to make attachment an active rather than a passive process? Once recognition is achieved, how does the organism attach to such a water-mineral interface?

By asking the latter question, we note that crystal surfaces in contact with an aqueous solution are not static but highly dynamic systems at the molecular scale. Dynamic processes, that is, formation and breakage of bonds, molecule movement via surface diffusion, movement of kink sites and steps at the fluid-solid interface are common basic processes that continually change the crystal surface and its topography at a range of length scales, particularly at disequilibrium conditions (for example, Lasaga, 1998). Despite this constantly changing surface, we have indicators in some cases that direct contact between microbes, for example dissimilatory metal reducing bacteria, and the solid mineral surface is required (Arnold and others, 1988; Myers and Nealson, 1988; Lovley and others, 1991; Nevin and Lovley, 2000). On the other hand, Rosso and others (2003) show experimental evidence for non-local dissolution effects, that is, dissolution features that are distant from the microbes on iron-oxide surfaces. To this end, one must always distinguish between direct and indirect effects - that are the result of direct microbial intervention via contact-mediated catalysis, and those that are mediated by metabolites (acids, bases, ligands, or redox-active compounds) excreted by microbes.

In the following, we compare and contrast three experimental studies that have provided glimpses of the complex picture. Many experiments have been performed with Geobacter and Shewanella sp. (for example, S. oneidensis MR1 or S. putrefaciens CN32) ${ }^{1}$ and a limited number of other microorganisms. Because there are only a few such model systems available, it is difficult to generalize these results. However, from the preliminary work, it is already clear that microorganisms may have a significant influence on crystal dissolution and growth kinetics and, therefore, on related macroscopic processes. Perhaps of more importance is the fact that in the "real world", only a small percentage of microbes that can be observed have been cultivated, so the range of other possible reactions (and thus mechanisms) remains a matter of speculation at this point.

\section{Forces Between Shewanella and Metal Oxide Surfaces}

A milestone in our understanding of microbe-solid interaction is the work by Lower and others (2001). In this study, the authors have measured the forces and changes of forces between living Shewanella MR-1 cells and (010) surfaces of goethite $(\alpha-\mathrm{FeOOH})$ and diaspore $(\alpha-\mathrm{AlOOH})$. Their in situ measurements with a biological force microscope (for example, Lower and others, 2000) in aerobic and anaerobic solutions showed that the forces [in $\mathrm{pN}$ ] and therefore the energies [in attoJoules] between MR-1 cells and the crystal surface changed during contact times of 0 to 45 minutes. Goethite and diaspore surfaces caused different results. While the measured forces changed significantly in the presence of a goethite surface, they were "indifferent" in the presence of diaspore when an anaerobic solution was oxygenated. Experiments with nonviable cells showed attractive forces (tens of $\mathrm{pN}$ ) between cells and goethite but no change of forces when changing anaerobic into aerobic conditions.

Lower and others concluded from their experimental results that Shewanella MR-1 is capable of recognizing crystal surfaces. Furthermore, MR-1 seemed to be able to 
modify the molecular arrangement at its outer cell membrane and react to molecular configurations present at the crystal surface. This study is a strong argument for microbial recognition of mineral surfaces and microbe response to these surfaces.

\section{Nonlocal Bacterial Electron Transfer}

Rosso and others (2003) performed an experimental study at strictly anoxic conditions in which they demonstrated that Shewanella putrefaciens CN32 dissolves the basal surfaces of hematite plates, a $\mathrm{Fe}$ (III) oxide $\left(\mathrm{Fe}_{2} \mathrm{O}_{3}\right)$, at locations that are not identical with points of microbial attachment. This observation is important because it demonstrates that direct contact between the crystal surface and the microbe is not required for the electron transfer to the oxide surface.

In a sequence of AFM images, Rosso and others were able to show that the hematite surface would dissolve "at the apices of growth centers" and through "structurally controlled etch channels". Another interesting observation was that the distribution of microbes on the crystal surface did not correlate with the microtopography of the surface. This result leads to the conclusion that reduction of $\mathrm{Fe}$ (III) in the crystal surface is not restricted to the areas of direct cell-surface contact.

The requirement for direct contact between cell and surface is indeed a key question for conceptual models and computer simulations. At least in some cases, such a requirement would necessitate the task of conceptually understanding microbial attachment within a highly dynamic crystal surface environment (see discussion below). Before Rosso's study, direct contact was certainly the prevailing conceptual model even if it could not be confirmed successfully experimentally (Rosso and others, 2003). The discovery of a link between a biosynthesized quinone that serves as an extracellular electron shuttle and the dissimilatory reduction of various electron acceptors by Newman and Kolter (2000) had already opened up a route for an alternative pathway of $\mathrm{Fe}$ (III) reduction and therefore for an alternative explanation. The experimental results reviewed here have demonstrated that such an alternative pathway does not require the direct contact between the cell and the surface, but these results do not exclude the possibility of such a pathway in other cases. Lüttge and Conrad (2004), and Davis and others (2004) have shown experimental evidence of a dissolution reaction between a microorganism and a crystal surface that occurs only at the contact regime with the attached microbe. We review this study next.

\section{Excavation of Non-Metal Oxide Surfaces}

Results of an experimental study published by Lüttge and Conrad (2004) show some different results. While Lower and others (2001) were fully aware that crystal surfaces are characterized by their microtopography and dislocation content, their study was not designed to address this issue. Lüttge and Conrad chose a different experimental approach using vertical scanning interferometry (VSI) to explore whether Shewanella oneidensis MR-1 would recognize not only the crystal surface but also certain high energy sites at the surface. Real crystals contain a large number of various lattice defects, that is, dislocations. The outcrops of line defects such as screw-dislocations are high energy sites and serve as centers for etch pit development in crystal dissolution. The question is if microorganisms such as MR-1 are able to recognize these sites that are distinctly larger than kink-sites at the single-molecular scale.

VSI and PSI (phase shifting interferometry) are relatively new, minimally invasive techniques in geochemical and geomicrobiological studies (for an in depth description see for example Lüttge and others, 1999, 2003; Lüttge, 2004; Arvidson and others, 2003, 2004a; Davis and others, 2004; Scott and others, 2004). Like atomic force microscopy, the light-optical method quantifies both surface topography and changes of surface topography during a dissolution, corrosion, or growth process. The resolution is vertically in the sub-angstrom to one-nanometer scale and laterally that of the 


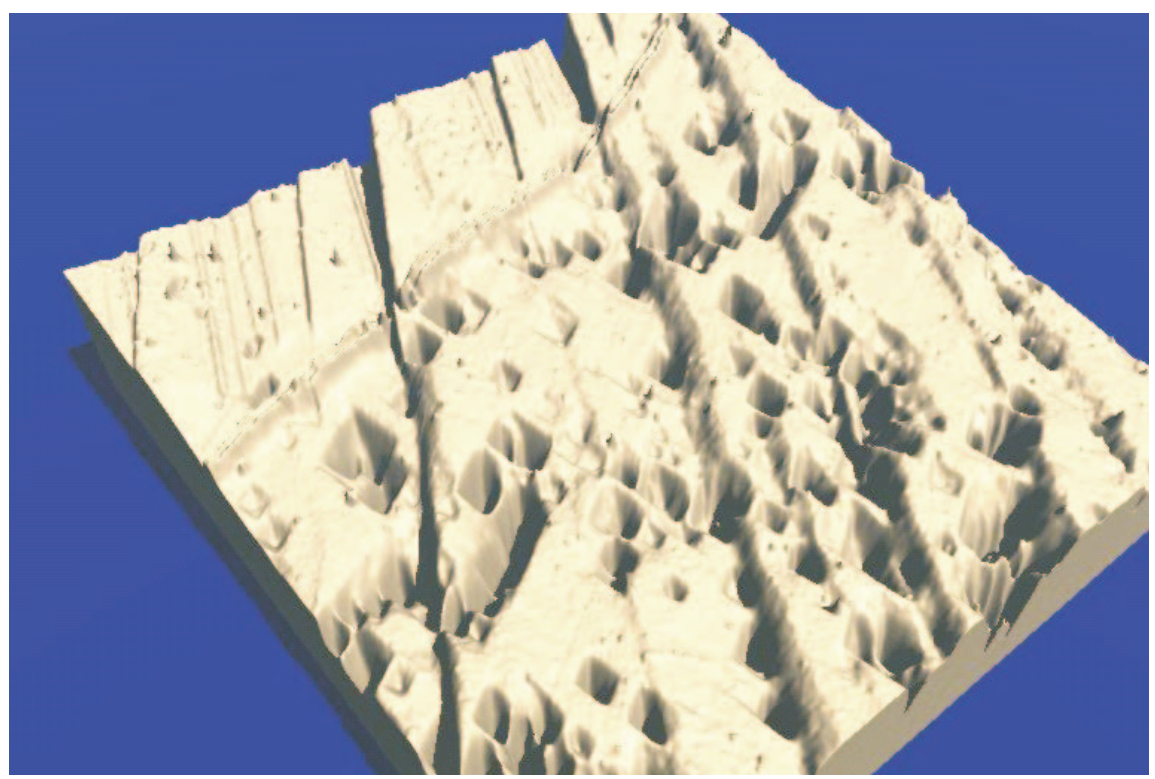

Fig. 1. Height map of a calcite surface with etch pits measured by vertical scanning interferometry (VSI). A 104 cleavage surface of calcite was dissolved at $25 \mathrm{C}$ and $\mathrm{pH}$ 8. The surface is characterized by the formation of flat-bottomed etch pits. The unpitted surface area was masked prior to the start of the dissolution experiment. The preserved surface area provides an internal reference for absolute height measurements.

particular Mirau objective used in the experiment. Unlike AFM, microscopic interferometry techniques provide a large field of view of up to one millimeter per scan. The scan time is fast, typically on the order of seconds. Using VSI, many microorganisms can be observed at the crystal surface at the same time, and their activities that cause changes in surface topography can be monitored and precisely quantified. In most cases, changes in surface height can be measured with 1 to 2 nanometer precision, in some cases even with 0.7 angstrom precision. Figure 1 shows a typical height map of a calcite surface with etch pits measured by VSI (MicroXam MP8, ADE-Phase Shift).

Lüttge and Conrad (2004) conducted experiments in which pairs of calcite cleavage surfaces were exposed to a growth medium both with MR-1 and without. They assumed that the pairs of mirror (104) cleavage faces would show mirror pattern of line-dislocation outcrops, for example, the outcrops of screw dislocations. The assumption was validated in control experiments, in which pairs of cleavage surfaces were exposed to an aqueous solution that would open the dislocations into etch pits. These experiments did indeed show a mirror pattern of etch pits. Further experiments demonstrated repeatedly that MR-1 would attach to the high-energy sites of the calcite surface, preventing regular, that is, crystallographically controlled etch pits from opening (compare also Davis and others, 2004). Live-dead control experiments confirmed that these results were only achieved when MR-1 was viable.

These results contain important implications for control of crystal dissolution kinetics. Lüttge and Conrad (2004) show that Shewanella oneidensis MR-1 (i) is capable of attaching to calcite surfaces; (ii) has a higher probability of attachment to the important high energy sites at the crystal surface than to less reactive sites; and (iii) is capable of forming trenches on the calcite surface at the cell-mineral interface (fig. 2). The trenches are 130 to $140 \mathrm{~nm}$ deep and about a third of the microbial diameter 


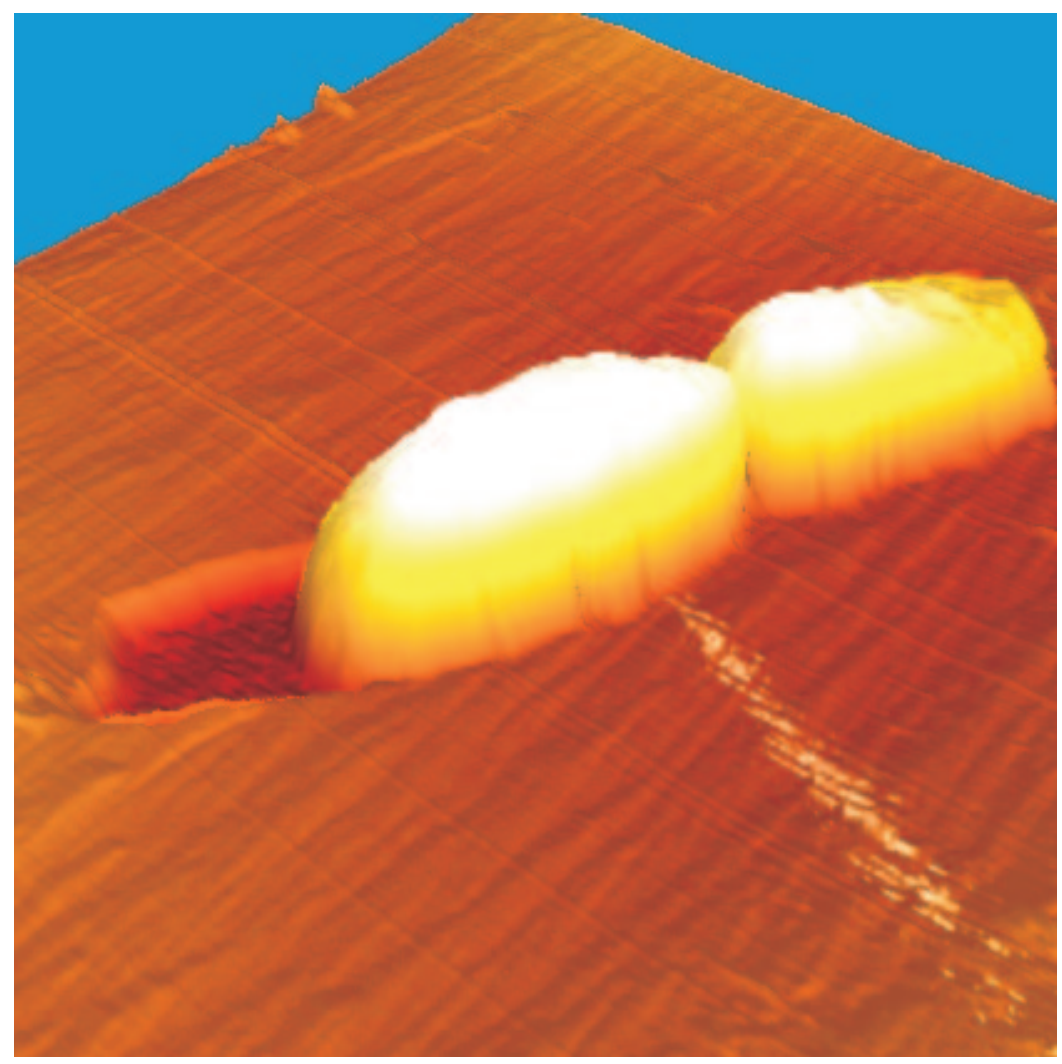

Fig. 2. Atomic force microscopy image of two MR-1 cells entrenched in a 104 calcite cleavage face. The cells are entrenched in a biotically formed pit. The pit is about 130 nanometers deep and its walls are well preserved (Davis and Lüttge, 2005).

( $\sim 400 \mathrm{~nm}$, and $\sim 2 \mu \mathrm{m}$ long). Trenches are created even if the aqueous solution is slightly oversaturated with respect to the carbonate substrate (Patch and others, 2002). At this time, it is too early to suggest that this behavior is a general pattern of microbial behavior and significantly more work needs to be done. Even if more work is necessary to evaluate the importance for natural systems quantitatively, these preliminary experimental results already indicate that microorganisms such as MR-1 potentially interfere with important abiotic water-rock reactions, and the implications of this important observation need to be taken into account.

Based on the discussion above, in the following section we will derive a relative simple approach to model and explore the effect that bacteria can have on fluidmineral interactions while abiotically-controlled dissolution or growth processes are already underway. Our approach uses parameterized Monte Carlo techniques, and we start our introduction with a short review of the use of this technique in abiotic systems.

MONTE CARLO SIMULATIONS IN CRYSTAL DISSOLUTION KINETICS

Even sophisticated analytical and imaging techniques such as AFM, VSI, XPS, Raman spectroscopy and others mentioned above can be applied only to directly accessible surface areas. Therefore, it is difficult to study the interactions at the interface between bacteria and the mineral surface directly. The microorganisms cover the location of interest. Strategies to remove microbes from the crystal surface (for 
example, Buss and others, 2003) are often difficult to employ and only reveal the surface after abandonment. That means we can study the result of microbial action at a certain point in time but not the process or mechanism that led to this result. In this situation, modeling efforts are an important tool to explore microbially-mediated processes in water-rock interactions. Stochastic approaches such as Monte Carlo techniques have already proven successful in our effort to study mineral dissolution and growth kinetics.

\section{Review of Previous Studies with Monte Carlo Simulations}

Gilmer (1976, 1977, and 1980) has used Monte Carlo simulation techniques successfully to the study of crystal growth. Based on this work, Lasaga and Blum (1986), Blum and Lasaga (1987), and Wehrli (1989a, 1989b) utilized this powerful technique to study crystal dissolution almost two decades ago. For a comprehensive overview and in depth discussion of the approach that is complementary to molecular dynamics (MD) calculations see Lasaga (1990, 1998), see also Philpot (2004). Earlier studies explored dissolution kinetics of mineral surfaces often in relatively crude molecular block models. Since then, the rapidly increasing speed of computers and the introduction of a new theoretical concept (Lasaga and Lüttge, 2001, 2003) for the dissolution of crystalline matter have provided the basis for further progress in crystal dissolution kinetics discussed below.

\section{The Stepwave Dissolution Model}

Lasaga and Lüttge (2004a, 2004b, 2004c) have recently presented a fundamental and quantitative description of abiotic crystal dissolution kinetics (see also Lüttge, 2004; Lüttge and Lasaga, unpublished). This work is based on their so-called stepwave model (Lasaga and Lüttge, 2001, 2003). In this model, crystal dissolution and growth processes are treated conceptually in a stochastic approach as a many-body problem. This approach is different from other approaches in geochemical reaction kinetics that usually seek to identify a rate-limiting step or process, such as the formation of a precursor complex (for example, Oelkers, 2001). The new model fully incorporates the three-dimensional crystal lattice and investigates its interactions with an aqueous solution. A major result of this approach was the prediction of 'stepwaves' that constantly emanate from the outskirts of etch pits and then travel across the entire crystal surface. The sketch in figure 3 shows that each stepwave will lower the crystal surface by a unit step height, $h$. Over time, this process causes the "global" or total surface-normal retreat that represents the overall dissolution rate, $R$, of the crystal at a given set of parameters.

Recently, we have observed this reaction mechanism in dissolution experiments of calcite 104 cleavage faces [see fig. 4 (Arvidson and Lüttge, unpublished), and also figures 7 and 11 in Arvidson and others (2004b) and Vinson and Lüttge (2005), respectively]. Fewless and Lüttge (unpublished) have reported stepwaves observed in barite dissolution, and Beig and Lüttge (unpublished, fig. 9B) in albite dissolution. Additional support for the validity of the stepwave model comes from experimental observations and measurements as well as theoretical considerations by Tang and others $(2001,2003,2004)$. Vertical scanning interferometry techniques (for example, Lüttge and others, 1999, 2003) and atomic force microscopy measurements have been used to determine reaction rates at different length and time scales, that is, step(wave) velocities at the nanometer scale and surface-normal retreat rates at the micron to millimeter scale. Dissolution rates measured for the same mineral but at different length and time scales are often inconsistent if extrapolated and compared directly. Using the stepwave model as the theoretical framework for such a comparison has led to a successful link of these 'different' rates (for example, Vinson and Lüttge, 2005). Building on these results, we have begun to develop a fundamental understanding of 


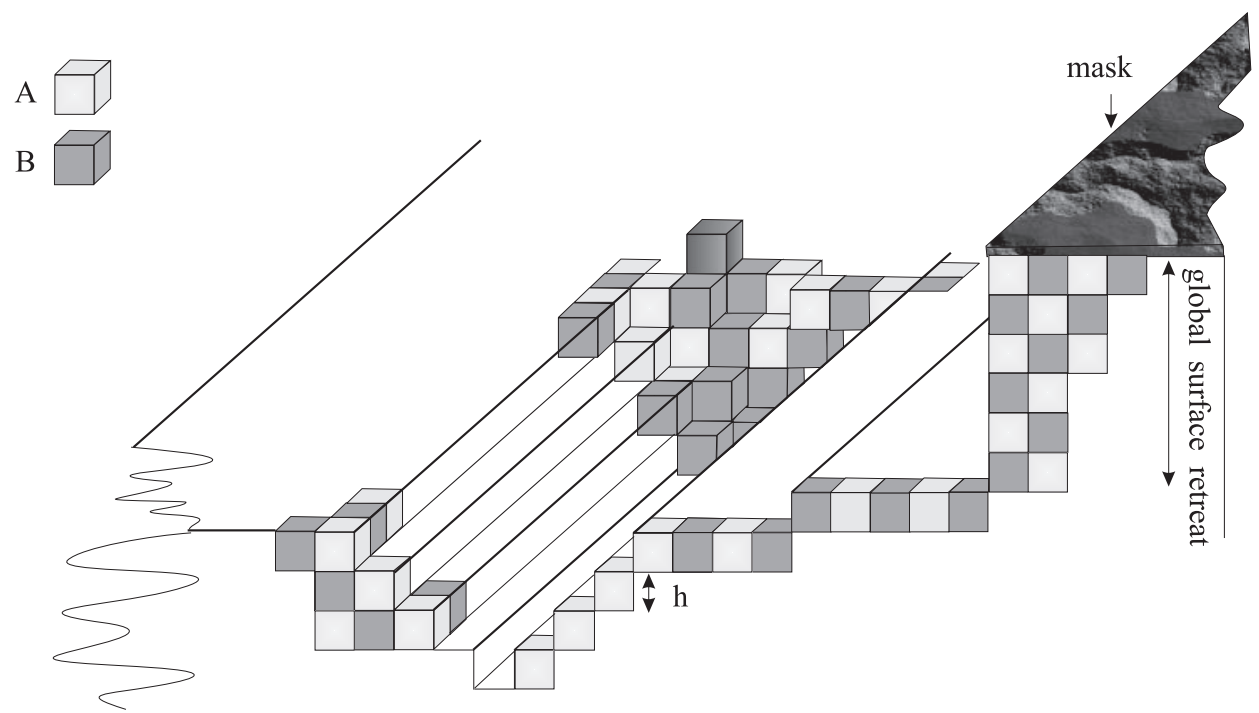

Fig. 3. Sketch demonstrating the generation of steps at an abiotically formed and controlled pit wall, the surface normal retreat caused by single-step movement, and the accumulated, global surface retreat that generates the overall dissolution rate of the crystal.

crystal dissolution. This task is a prerequisite for a quantitative description of more complex mineral dissolution and growth processes involving microorganisms.

\section{Monte Carlo Approach to Crystal Dissolution Kinetics-The Model}

Abiotic crystal dissolution kinetics have been explored theoretically by using parameterized Monte Carlo simulations. Starting with relatively simple structures such as $\mathrm{AB}$ and $\mathrm{A}_{3} \mathrm{~B}$ models used as analogies for feldspar endmembers (Lasaga and Lüttge, 2004a, 2004b; and Lüttge, 2004), this work has progressed to incorporate full crystal structures such as albite (Lüttge and Lasaga, unpublished). Feldspars are aluminosilicates where $\mathrm{Si}$ and $\mathrm{Al}$ tetrahedra are linked by oxygen-bridging bonds. Therefore, the $\mathrm{AB}$ and $\mathrm{A}_{3} \mathrm{~B}$ models were used to represent aluminosilicates with the assumption that the cations calcium and sodium do not alter the dissolution kinetics significantly. The $\mathrm{AB}$ model then represents anorthite with a 50:50 ratio of $\mathrm{Si}-\mathrm{O}-\mathrm{Al}$ to $\mathrm{Si}-\mathrm{O}-\mathrm{Si}$ bonds. The $\mathrm{A}_{3} \mathrm{~B}$ model represents albite with a $25: 75$ ratio of Si-O-Al to Si-O-Si bonds. Al-O-Al bonds are omitted in both cases because of the $\mathrm{Al}$ avoidance rule (Tossel, 1993; Lee and Stebbins, 1999). The approach also incorporates important theoretical concepts such as flickering bonds and the inclusion of bond-breaking and -formation as elementary reactions, in addition to the basic processes such as molecule surface attachment, detachment, and diffusion. Today, the modeling effort using the full crystal structure is advanced enough to treat plagioclase feldspar with solid solutions and order-disorder relationships (Zhang and Lüttge, unpublished).

So far, we have used Monte Carlo techniques to explore the kinetics of crystal dissolution in detail. Of particular interest was the effect of strain fields on the dissolution kinetics. Such strain fields are generated by screw dislocations, and we know from experimental work of the importance of these surface features for the dissolution mechanism and rate. In addition, we have studied in detail the movement of steps across a crystal surface, the interaction of differently oriented steps with the surface and phenomena such as step bunching that can significantly slow down the overall dissolution process. The correct parameterization of Monte Carlo simulations 

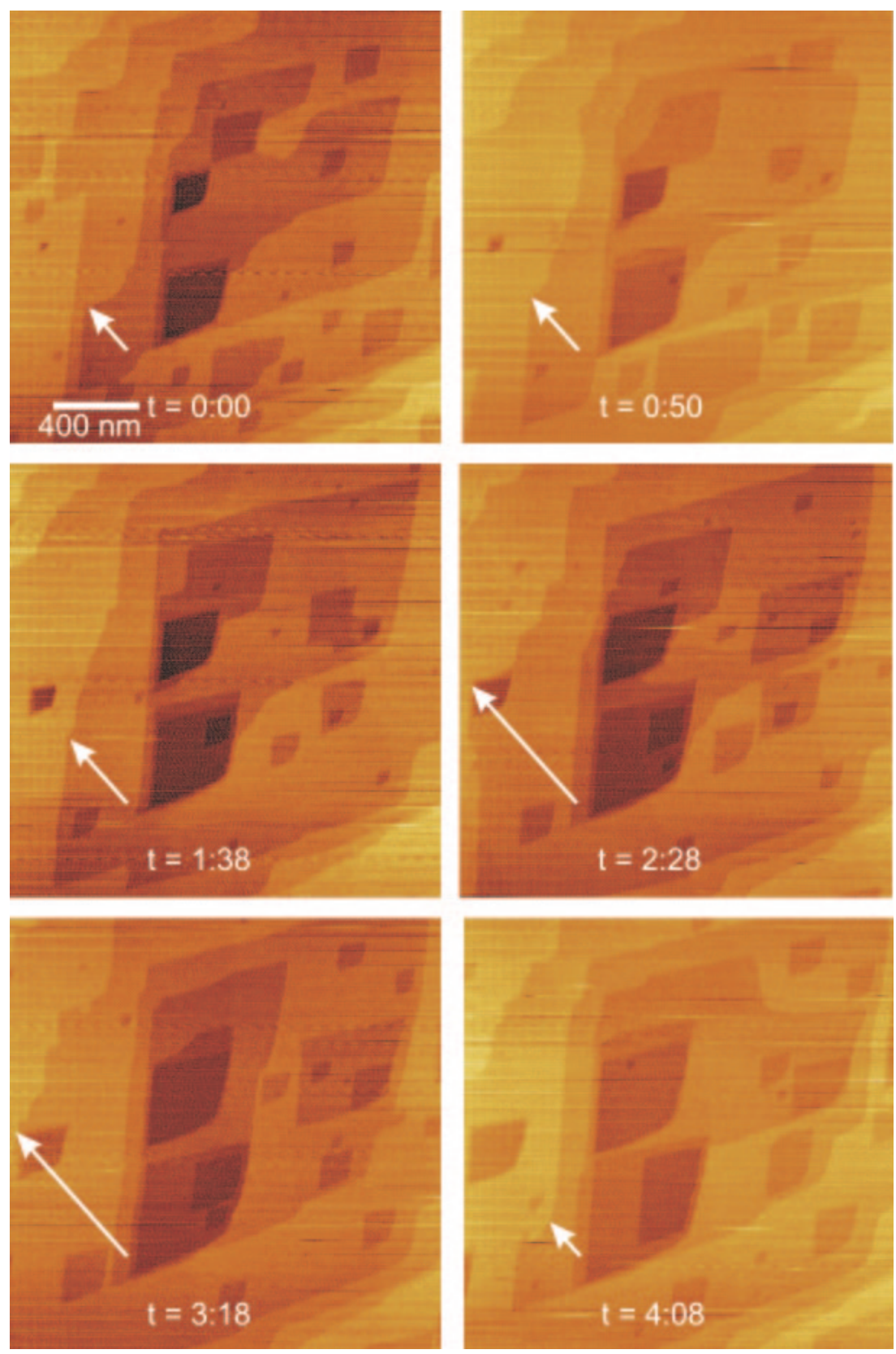

Fig. 4. Stepwave sequence on calcite $\left(2 \times 2 \mu \mathrm{m}\right.$ frame, $\left.\mathrm{pH} 5.98, P \mathrm{CO}_{2} \sim 0, \mathrm{NaCl}=4.4 \mathrm{mM}\right)$, showing progressive right to left advance of high kink density step (arrowhead) as a function of time (minutes: seconds). Last frame at $t=4 \mathrm{~min}$. and $8 \mathrm{sec}$. shows initiation of next sequence, beginning with cannibalization of upstream etch pits (Arvidson and Lüttge, unpublished).

is important, and key parameters can be often obtained from the literature or estimated in the initial approach. However, theoretical calculations using ab initio, Hartree-Fock, and density functional theory (DFT) techniques can also be used to 
improve the Monte Carlo simulations significantly. As an example, Xiao and Lüttge (unpublished) have generated adsorption and activation energies for breaking Si-O-Si and $\mathrm{Si}-\mathrm{O}-\mathrm{Al}$ bonds in alumino-silicates incorporating solvations shells into the calculations and immersing the atomic clusters into a dielectric continuum. The results show significantly lower energies than previously published data.

One of the important general results of these studies of crystal dissolution is the shift in our view of the function of etch pits in crystal dissolution kinetics. The key aspect is that mass removal at the etch pit itself can be insignificant compared to the total mass removal. More importantly, the etch-pit rim may be a constant source for stepwaves that constitute the majority of mass removal from the crystal surface. This concept will predictably modify our view of the reactive surface area that assumed that reactive parts of the surface were merely limited to the pits and steps while the flat terraces remained mainly inactive. All results of the abiotic studies of crystal dissolution kinetics are reported in Lasaga and Lüttge (2004a, 2004b), Lüttge (2004), Lüttge and Lasaga (unpublished), and Zhang and Lüttge (unpublished).

Microbial cells that attach to minerals, metals, and other solids produce extracellular polymers extending from the outer cell membrane, forming a biofilm (for example, Characklis and Marshall, 1990; Little and others, 1997a) give an excellent overview of the mechanism and processes of biofilm formation). This observation is of concern not only to microbiologists but also to geochemists interested in mineral-water interactions. Microbial cells within the biofilm may maintain vastly different conditions at the mineral-fluid interface with respect to $\mathrm{pH}$ and fluid speciation. Such different conditions, however, are likely to cause significantly different crystal dissolution behavior, not only as predicted thermodynamically from the bulk solution (Little and others, 1997a) but also as predicted by abiotic dissolution kinetics. Therefore, we seek to expand the Monte Carlo simulations based on our abiotic models. Next, we report a simple approach to incorporate local effects of microbial participation on mineralwater interactions and dissolution kinetics. That means we propose a strategy to explore and predict stochastically effects of microbial activities at the water-crystal interface. Note that this approach observes the activities at the crystal surface only and does not simulate the processes at the microbial cell membrane. Therefore, our approach is centered on the geochemical side. However, we simulate etch pit formation in an $\mathrm{AB}$ crystal that is no longer controlled exclusively by the interplay between the crystal lattice, its dislocations, and the abiotic aqueous solution, but also by the chemical activities of microbial cells attached to the surface. Commonly, we write an empirical rate law for the abiotic dissolution of a given crystal in the form

$$
\text { Rate }=k A(t) a_{H^{+}}^{n_{H}} a_{a_{\text {inh }}}^{n_{r}} a_{a_{\text {catal }}}^{a} f(\Delta G)
$$

where Rate is the overall rate, $k$ is the rate constant, $A(t)$ is the surface area as a function of time, $a_{\mathrm{H}+}$ represents the $\mathrm{pH}, a_{\mathrm{inh}}$ and $a_{\text {catal }}$ are the activities of inhibitors and catalysts in the reaction, if present. $f(\Delta G)$ is a function describing the dependence of the overall rate on the driving force of the reaction with

$$
\Delta G=R T \ln \frac{\left(a_{A} a_{B}\right)}{\left(a_{A} a_{B}\right)_{e q}}
$$

where $R$ is the gas constant, $T$ the temperature, and $\left(a_{\mathrm{A}} a_{\mathrm{B}}\right) /\left(a_{\mathrm{A}} a_{\mathrm{B}}\right)_{\mathrm{eq}}$ is the quotient of the activity product of $\mathrm{A}$ and $\mathrm{B}$ molecules actually in the solution and the activity product at equilibrium (solubility product). Microbial activity can alter almost all parameters in this rate law. Bacteria may influence these parameters directly, for example, by uptake of ions or electron release or indirectly, by proton pumping. Proton pumping will change the $\mathrm{pH}$ value of the solution and consequently will 
change the saturation state. In contrast to this simple approach, Jin and Bethke (2003) have derived a powerful rate law describing microbial respiration as the product of a rate constant, biomass concentration, and additional terms that account for the kinetics of electron-donating and accepting reactions as well as a thermodynamic term. The latter term accounts for the energy that is "available in the microbe's environment". In our Monte Carlo model we will explore the effect of changes in saturation state and bond strength between A and $\mathrm{B}$ molecules. Changes in $\mathrm{pH}$ cannot be studied directly, yet, but later computer codes will incorporate this parameter. However, $\mathrm{pH}$ is considered already indirectly because it enters via $\Phi$; (that means by changing $\Phi_{A B}$ we are effectively changing the $\mathrm{pH}$ ). Note that the current simple model does not contain assumptions about the microbial attachment mechanism itself. We treat this as a separate problem that will need special attention at a later time. However, we will include a crude attempt to incorporate the effect of the beginning of a biofilm. This initial stage is characterized by adsorption of organic macromolecules to the wetted crystal surface.

The model calculations will explore the effect of local changes of the parameters listed above on the dissolution behavior of the entire crystal surface. We will investigate in particular the implications of the local changes on surface features such as a dislocation strain field, steps, and their movement across the crystal surface. These are critical elements in the abiotic dissolution process.

\section{Model-Parameters, Settings, and Assumptions}

Our cubic $\mathrm{AB}$ model uses periodic boundary conditions and assumes the presence of A-B bonds, only. Consequently, both, A-A and B-B bonds are not allowed in this simulation. This scenario is different from the one used in Lasaga and Lüttge (2004a) where an $\mathrm{AB}$ model was used to represent the Ca-feldspar anorthite.

Here, we are using an $\mathrm{AB}$ model simply to demonstrate the effect of bacterial attachment and interaction with a crystal surface. Therefore, it is justified and useful to simplify the solid model structure as much as possible, that is, only A-B bonds are allowed. The bond strength parameter $\Phi_{\mathrm{AB}} / k T$ is set to 2.49 . This choice is representative for some important non-silicates; carbonates for example have bond strengths between 2 and 4 . In contrast, Lasaga and Lüttge (2004a, 2004b) varied the bond strength for aluminosilicates between 4 and 12 .

In all calculations of the present study, the grid size is $80 \times 80$ molecular A and B blocks. The entire crystal surface is therefore 6,400 blocks. Next, we separate a square field of 1,600 blocks $(40 \times 40$ molecular blocks $)$ that represents the area of microbial cover and interaction, leaving the remaining surface with 4,800 blocks. The small area of 1,600 blocks is much smaller than an actual microbe: for example, Shewanella oneidensis MR-1 has an average size of about 2 microns length and about 500 nanometers diameter. However, this size is large enough to begin exploring the principal effects that a local area with different parameters can have on a crystal surface. Future work will modify this limitation in geometry and size. The entire solution in contact with the mineral surface is undersaturated, and the saturation state of $\mathrm{A}+\mathrm{B}$ in solution in contact with the $\mathrm{AB}$ surface is defined by $\Delta \mu_{\mathrm{A}}$ and $\Delta \mu_{\mathrm{B}}$ (see Lasaga and Lüttge, 2004a).

Note that the time step between different stages of equal numbers of blocks removed is not necessarily the same. The reasons for this non-linearity of the time step is twofold: (i) to quantify the basic processes in the model such as detachment, attachment, and surface diffusion, we have introduced a general frequency factor $v$ $\left(\mathrm{sec}^{-1}\right)$ into the calculations to set the time scale for rate constants. But

$$
\Delta t=\mathrm{a} / v
$$




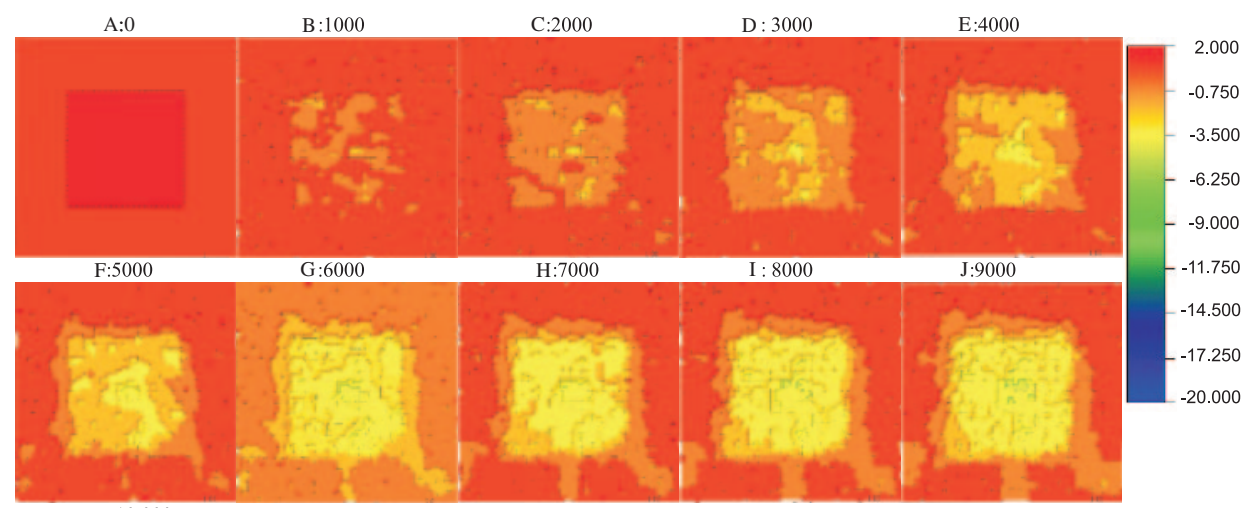

$\mathrm{K}: 10,000$

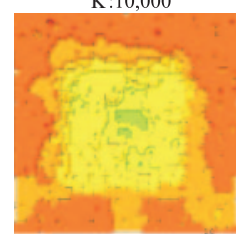

Fig. 5. Sequence of model results showing the surface topography after every 1,000 atomic blocks are removed; the initial surface is flat. Figure $5 \mathrm{~A}$ shows the bacterial interaction area in bright red; entire model size: $80 \times 80$ blocks; area of increased undersaturation: $40 \times 40 ; \Delta \mu_{\mathrm{A}} / k T=\Delta \mu_{\mathrm{B}} / k T=-9.0$; only surface diffusion of adatoms is allowed; saturation state of the outer area: $\Delta \mu_{\mathrm{A}} / k T=\Delta \mu_{\mathrm{B}} / k T=-0.5$; no surface diffusion is allowed; bond strength of $\mathrm{A}-\mathrm{B}$ bonds, $\Phi_{\mathrm{AB}} / k T=2.49$, is constant for the entire model area.

where a is chosen so that at least one of the basic processes (that is, dissolution, attachment, and diffusion) takes place in the time interval $\Delta t$. In this uniform time unit, the numbers of different basic processes per unit time are not necessarily the same and, moreover, vary with the dissolution process. (ii) Our sequences of images below show always the net results of every 1000 molecular blocks removed. Between these stages, all three basic processes occur at the model surface. While the net result is 1000 blocks detached, the time interval is the weighted time sum of all these processes. For an in depth discussion of this effect, see Lüttge and Lasaga (unpublished).

All calculations assume that the saturation state of the solution and the arrival rate of A and B molecules at the surface are constant, while the detachment rate of A and B molecules can vary according to the dissolution progress. Further, we will make the important assumption that there is always a water layer present between the microbial cell and the crystal surface that allows transport of dissolved molecules from the contact interface into the bulk solution. In short, we do not consider direct cellmineral contact. Rosso and others (2003) have demonstrated that this is a realistic scenario. This strategy also avoids a priori assumptions of transport-limited kinetics. If dissolution kinetics do become transport controlled, this would be a result of the model calculations.

RESULTS FROM MONTE CARLO SIMULATIONS

\section{Results from Calculations Using a Flat, Undisturbed Crystal Surface}

We start our exploration with the simplest case: a surface that is initially atomically flat and lacks the strain field characteristics of screw dislocation outcrops (fig. 5A). In this figure, the area that simulates the effects of microbial interaction is marked in dark red. To generate any significant dissolution, the surface is seeded with "point defects", that is, a few randomly chosen molecules that are removed. These defects give rise to 

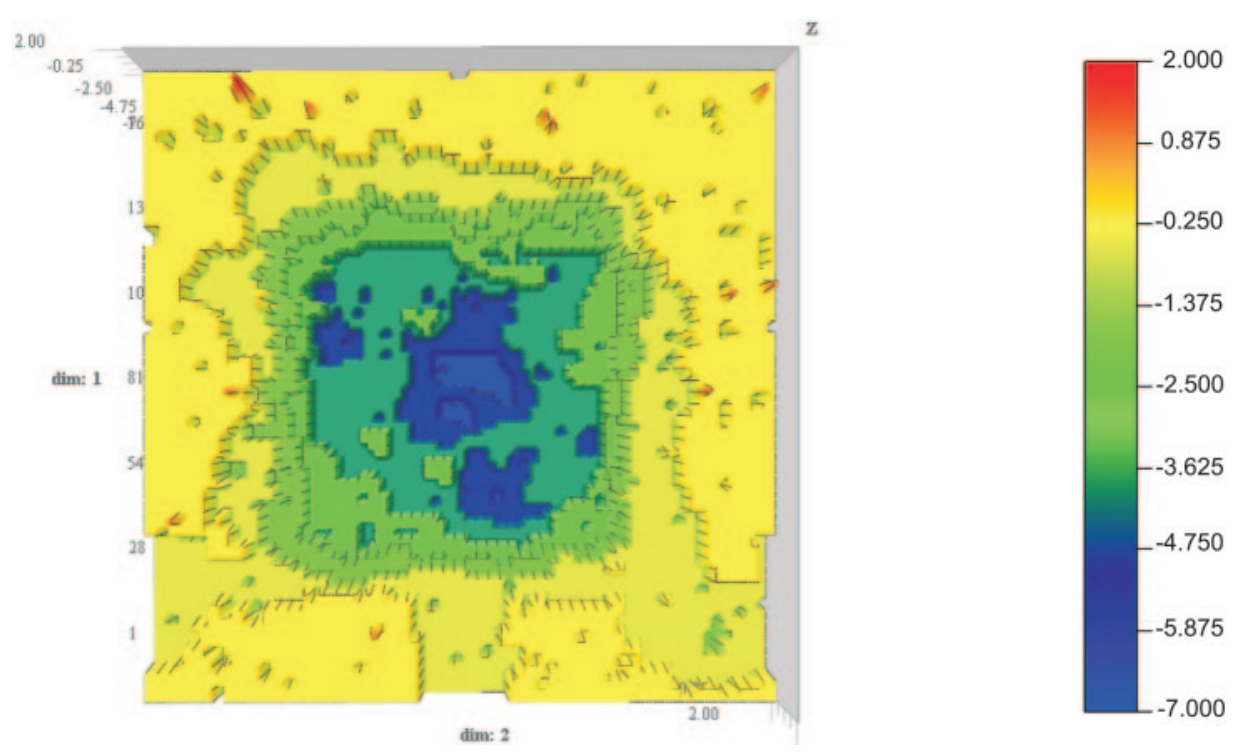

Fig. 6. Color coded surface topography of figure $5 \mathrm{~K}$ in higher magnification; 10,000 atomic blocks have been removed at this stage; model parameters are given in figure 5; the plot shows that the pit is depending and also spreading laterally.

the opening of small pits one monolayer in depth (fig. 5B). Figures 5A-K shows the development of the dissolving $\mathrm{AB}$ surface. Although the surface as a whole undergoes dissolution, the localized lower saturation state leads quickly to the formation of a rapidly growing pit. Note that in this simulation only two-dimensional surface diffusion of A- and B-adatoms is permitted. To produce a significant hole within a reasonable time frame without the presence of a strain field, we generated a large difference in saturation state between the 'microbe covered' area and the rest of the surface. The parameters were set so that the solution over the bacteria covered area was significantly more undersaturated $\left(\Delta \mu_{\mathrm{A}} / k T=-9.0, \Delta \mu_{\mathrm{B}} / k T=-9.0\right)$ than the rest of the surface $\left(\Delta \mu_{\mathrm{A}} / k T=-0.5, \Delta \mu_{\mathrm{B}} / k T=-0.5\right)$. Figures $5 \mathrm{~B}-\mathrm{K}$ shows the development of the pit. Figure 6 is a magnification of figure $5 \mathrm{~K}$ (different color scheme) and shows the surface after 10,000 molecular blocks have been removed. The pit differs from those observed in the experimental studies with Shewanella MR-1 on calcite cleavage faces (compare Lüttge and Conrad, 2004). In the simulation, the rim of the pit is still active as in the abiotic, crystallographically controlled scenario, and thus the pit is spreading quickly laterally. In contrast, the large majority of pits associated with MR-1 in the calcite experiments showed a passive rim whose movement was apparently inhibited. The pits themselves showed mainly the negative body shape of the organisms (for example, fig. 7). To modify pit development and address this issue, we repeated the simulation with the following important modification.

Lüttge and Conrad (2004) observed in their experimental study with MR-1 on calcite surfaces that a biofilm began to form shortly after attachment of MR-1 to the surface. This observation is quite common, and MR-1 is known to form biofilms during attachment to many other surfaces (Nealson and Little, 1997; Nealson and Stahl, 1997; Little and others, 1997b; Larsen and others, 1998). The biofilm, however, has proven to be quite sticky and covers the mineral surface even in the presence of an aqueous solution. Here, we are mainly interested in the aspect that the biofilm molecules could have an inhibitory effect on the dissolution kinetics of the etch pit rim. In the 


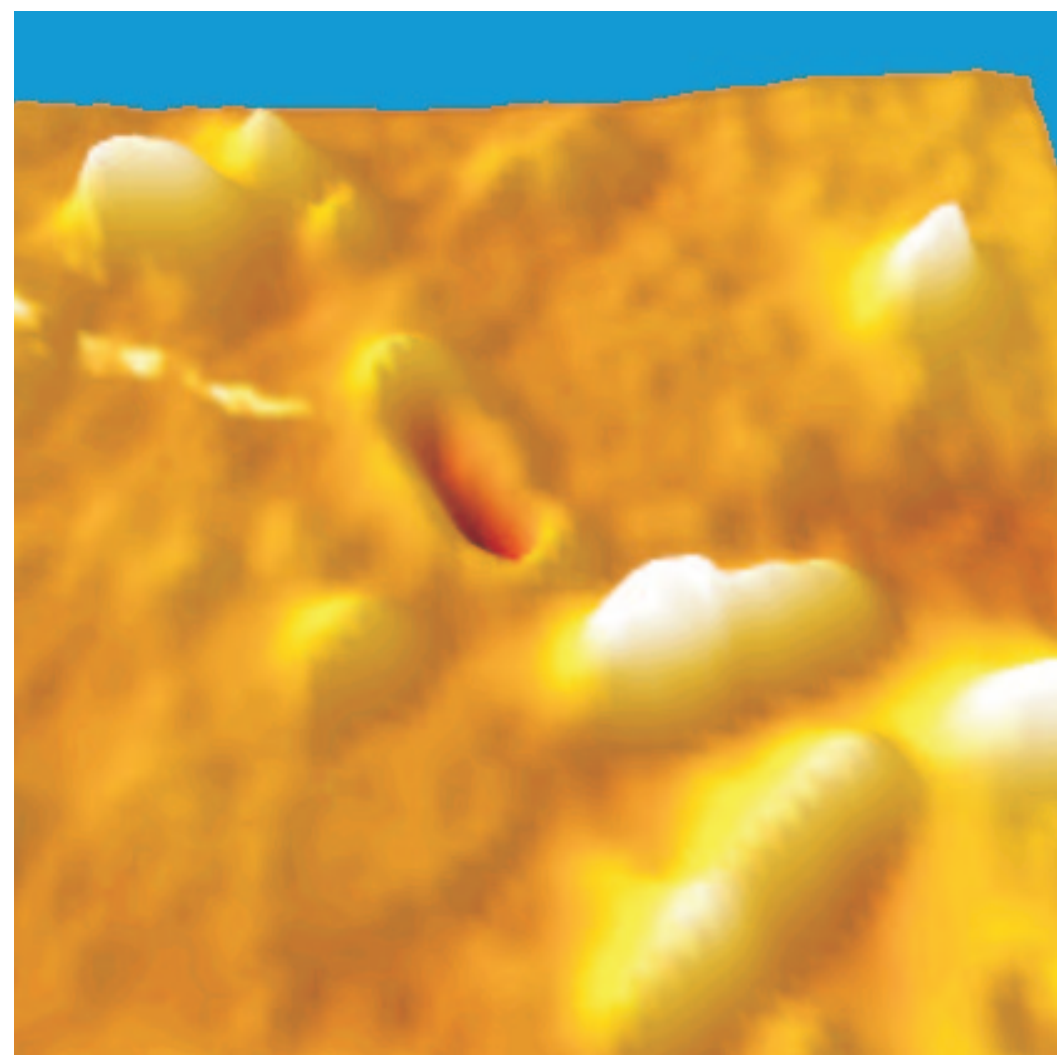

Fig. 7. Vertical scanning interferometry image of a trench formed by a single MR-1 organism in a calcite cleavage face. The microbial cell has been removed. The pit is about 2 microns long and about 130 nanometers deep; note the elevated rim surrounding the pit (Davis and Lüttge, 2005).

simulation, we added a narrow monomolecular layer of C-molecules around the area that would simulate the contact area of an MR-1 organism (fig. 8A). This layer of C-molecules simulates a polysaccharide halo surrounding the organism. The narrow monomolecular rim represents the early stage of biofilm formation. Although an actual biofilm would grow, for simplicity it is kept constant in the simulation. In future work, this will be changed into a dynamic development and more complex composition. However, even this obvious oversimplification leads to some interesting results and is in agreement with our goal to simulate first order effects.

The results of these simulations are shown in figures 8A-L. Most parameters in the new simulation are the same as in the previous one with the exception of the saturation state over the microbe-covered area. This area is now significantly less undersaturated than in the previous case, that is $\Delta \mu_{\mathrm{A}} / k T=-1.0$ and $\Delta \mu_{\mathrm{B}} / k T=-1.0$ compared to $\Delta \mu_{\mathrm{A}} / k T=-0.5$ and $\Delta \mu_{\mathrm{B}} / k T=-0.5$ for the rest of the surface. Also, the microbecovered area is now oval in shape and has a higher kink site density on two sides (see fig. 8).

Figures $8 \mathrm{~A}-\mathrm{L}$ is a time sequence showing the development of the surface topography at intervals of constant mass removal (1000 molecular blocks). The area covered by our virtual "bacteria" is developing smoothly into an oval-shaped etch pit surrounded by a rim covered with $\mathrm{C}$ molecules. The inhibitory effect of C-molecules is strong enough so that the rounded sides of the pit representing high kink-site densities are 


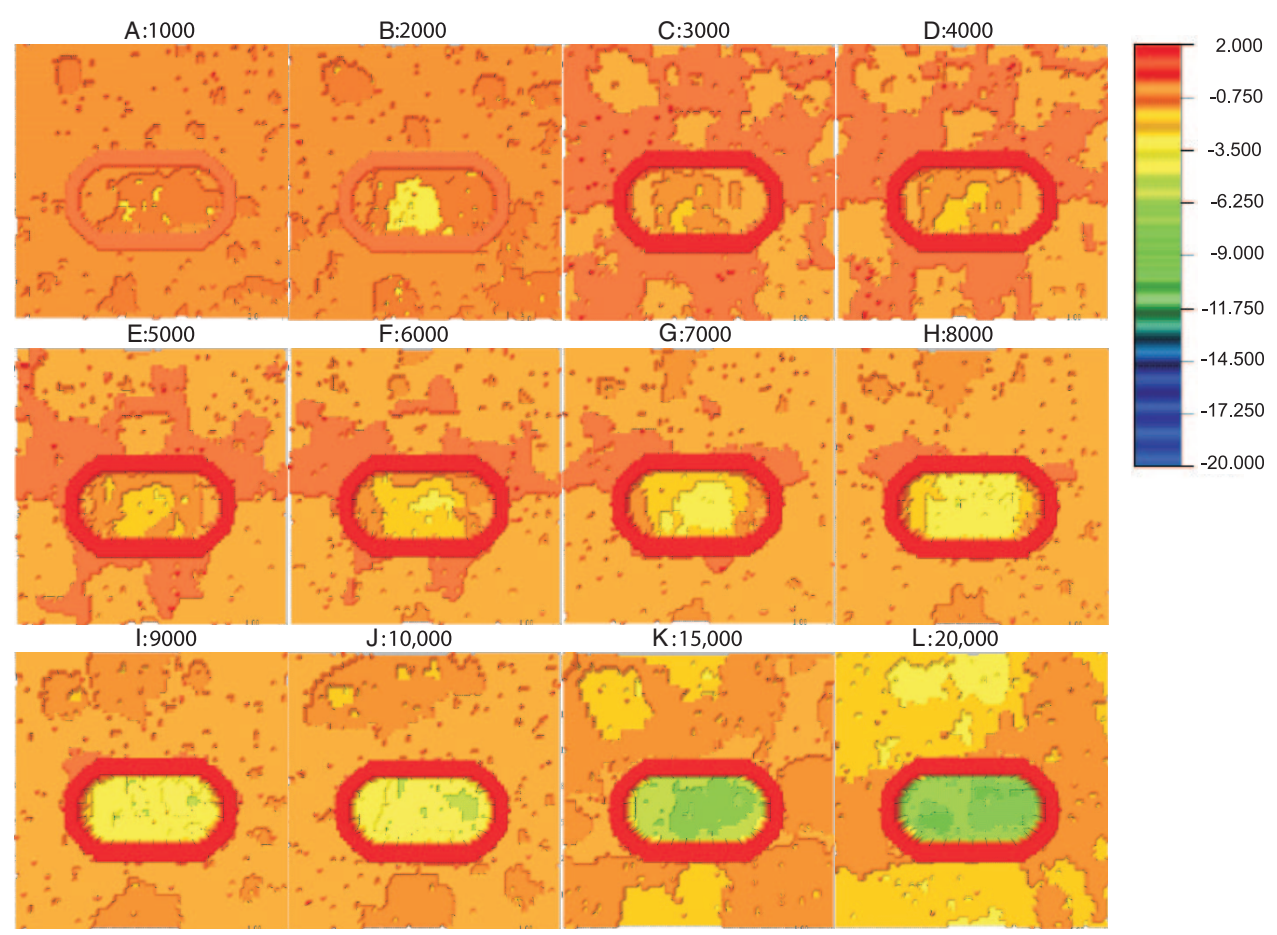

Fig. 8. Sequence of model results showing the surface topography after every 1,000 atomic blocks are removed; the initial surface is flat but a rim of C-molecules has been added around the bacteria covered area; entire model size: $80 \times 80$ blocks; area of increased undersaturation: $20 \times 30 ; \Delta \mu_{\mathrm{A}} / k T=\Delta \mu_{\mathrm{B}} / k T=-1.0$; saturation state of the outer area: $\Delta \mu_{\mathrm{A}} / k T=\Delta \mu_{\mathrm{B}} / k T=-0.5$; no surface diffusion is allowed; bond strength of A-B bonds, $\Phi_{\mathrm{AB}} / k T=2.49$, is constant for the entire model area.

not affected by the abiotic dissolution process. This result is in good agreement with the experimental observations. In summary, a relatively small local difference in saturation state over a crystal surface can lead to etch pits that are shaped by the inhibitory effect of molecules on the upper pit rim. These pits do not show the typical symmetry of the crystal lattice. Most importantly, this simulation shows that generation of steps and stepwaves can be suppressed by a layer of molecules that serve as inhibitors.

\section{Results from Calculations with Reduced Bond Strength}

Before we explore further the effect of microbial activity on surface features such as strain fields and steps, we want to investigate if the effect of a locally different saturation state can be repeated with lower bond strength between surface atoms. This scenario is realistic for cases where microbes would shuttle electrons to the crystal (oxide) surface as reported by Rosso and others (2003). In the following simulation, we keep the saturation state the same over the entire model surface $\left(\Delta \mu_{\mathrm{B}} / k T=\right.$ $\left.\Delta \mu_{\mathrm{A}} / k T=-2.0\right)$. In contrast to the previous simulation, we reduce the bond energy between $\mathrm{A}$ and $\mathrm{B}$ molecules within the microbe covered area to $\Phi_{\mathrm{AB}} / k T=2.2$ compared to $\Phi_{\mathrm{AB}} / k T=2.49$ for the rest of the surface. Figures $9 \mathrm{~A}-\mathrm{L}$ demonstrates that there is no significant difference on the resulting surface topography than in figures $8 \mathrm{~A}-\mathrm{L}$. Local changes in both saturation state and bond strength produce similar results with respect to surface topography on dissolving mineral surfaces. 


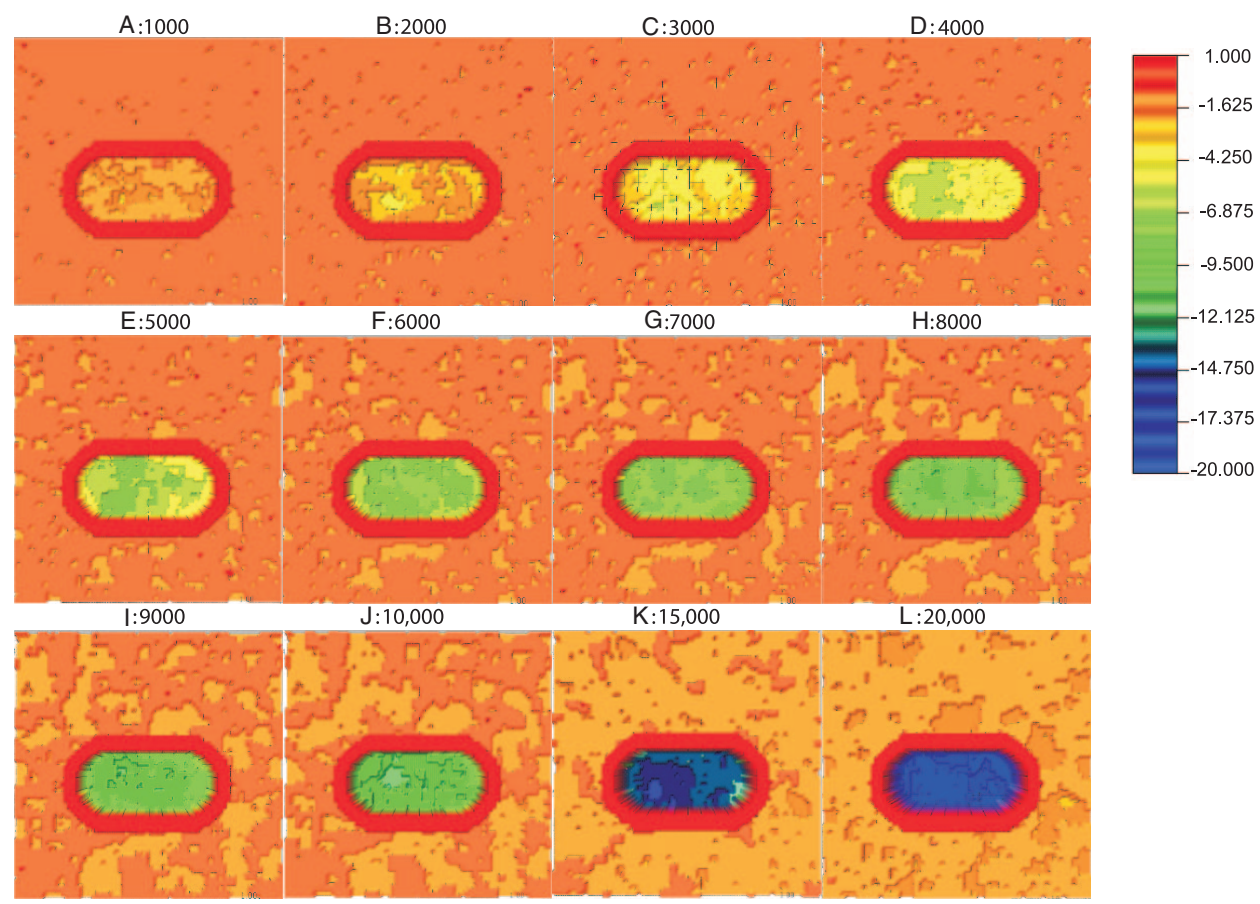

Fig. 9. Sequence of model results showing the surface topography after every 1,000 atomic blocks are removed; the initial surface is flat and has a rim of C-molecules surrounding the bacteria covered area; entire model size: $80 \times 80$ blocks; the undersaturation for the entire model area is $\Delta \mu_{\mathrm{A}} / k T=\Delta \mu_{\mathrm{B}} / k T=-2.0$; no surface diffusion is allowed; bond strength of A-B bonds, in the outer area is again $\Phi_{\mathrm{AB}}=2.49 \mathrm{kT}$, while the bond strength of the bacteria covered area is slightly lower, $\Phi_{\mathrm{AB}}=2.2 \mathrm{kT}$. The result is very similar to that shown in figure 8 .

\section{Results from Calculations Using a Flat Crystal Surface with a Local Strain Field}

The preceding model results were obtained from simulations that did not consider the presence of a strain field in the crystal lattice. Dislocations are common in crystals and cause such a strain field. Therefore, it is interesting to explore the effect of a strain field that represents a line defect like a screw dislocation in our next experiments. We repeat the calculations conducted before but with the addition of a strain field. The strain energy of the screw dislocation is given by equation (Blum and Lasaga, 1987)

$$
u(r)=\frac{u b^{2} /\left(8 \pi^{2} K\right)}{r_{h}^{2}+r^{2}}
$$

where $u(r)$ is the strain energy density, $\mu$ is the shear modulus (in ergs $/ \mathrm{cm}^{3}$ ), $b$ is the magnitude of the Buerger's Vector $(\AA), r_{h}(\AA)$ fixes the upper limit on the strain energy (for example, at $r=0$ ), and $r$ is the distance from the dislocation line $(\AA)$. $K$ is a constant that describes the relative contribution of screw and edge components in the dislocation strain field and $K=1$ for a pure screw dislocation. We locate the strain field at precisely the area that represents the microbe-covered surface. Such a scenario is realistic because Lüttge and Conrad have shown that MR-1 organisms attach with higher probability to exactly these spots on the crystal surface. Strain fields that are caused by dislocation outcrops at the crystal surface represent high-energy sites at the nanometer to micron scale. They are key locations of the surface microtopography for 

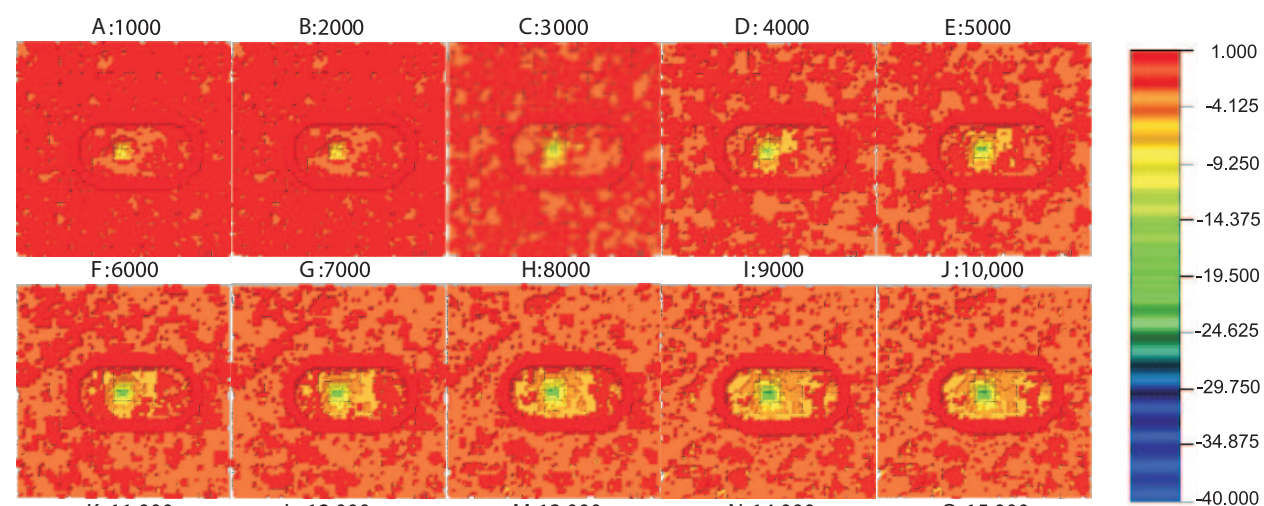

$\mathrm{H}: 8000$

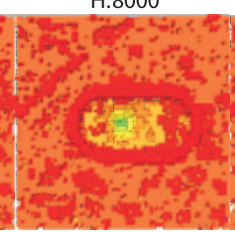

I:9000

$\mathrm{J}: 10,000$

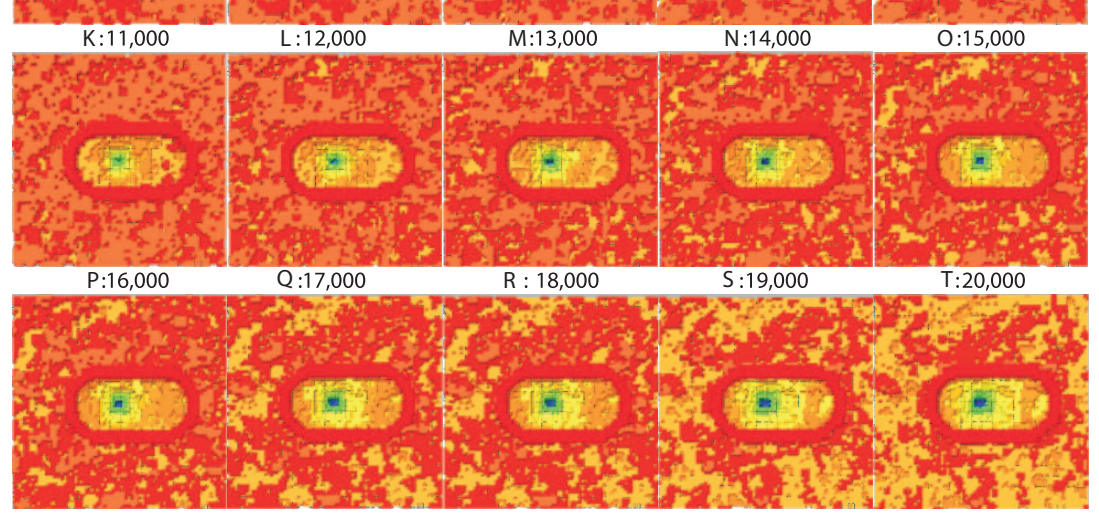

Fig. 10. Sequence of model results showing the surface topography after every 1,000 atomic blocks are removed, for a total of 20,000 blocks removed; the initial surface is flat, has a rim of C-molecules around the bacteria covered area; in addition, a strain field representing a screw dislocation was added; entire model size: $80 \times 80$ blocks; area of increased undersaturation: $20 \times 30 ; \Delta \mu_{\mathrm{A}} / k T=\Delta \mu_{\mathrm{B}} / k T=-1.0$; saturation state of the outer area: $\Delta \mu_{\mathrm{A}} / k T=\Delta \mu_{\mathrm{B}} / k T=-0.5$; no surface diffusion is allowed; bond strength of A-B bonds, $\Phi_{\mathrm{AB}} / k T=2.49$, is constant for the entire model area. The height maps show a quickly deepening hole inside the bacteria covered area.

both dissolution and growth. Figures $10 \mathrm{~A}-\mathrm{L}$ is again a time sequence that shows the development of surface microtopography. Each image shows the situation after a total of 1000 molecular A- and B-blocks have been removed from the model surface. Recall that the time scale between the various stages is likely to be different.

Figures 10A-L show the formation and development of a deep hole caused by the strain field within the larger pit of the microbe-covered area. The rest of the crystal surface shows the typical microtopography caused by the slower abiotic dissolution. The rate versus time plot in figures $11 \mathrm{~A}$ and $\mathrm{B}$ show the differences in rate between the two processes (compare with figs. 8 and 10 above). The dissolution rate at the microbe-mineral contact area is significantly increased. Recall that our simulations always mimic an open system, in which saturation state of the solution is constant in space and time, although locally lower above the microbe-surface area than the rest of the model surface.

\section{Results from Calculations Using a Flat, Stepped Crystal Surface}

The most important phenomenon during both crystal growth and dissolution is the movement of steps across the surface. The effect of microbial attachment was explored with a simulation and is discussed in detail below. Figures 12A-T show the results of the simulation. To the scenario of the flat surface, we have added crystallo- 

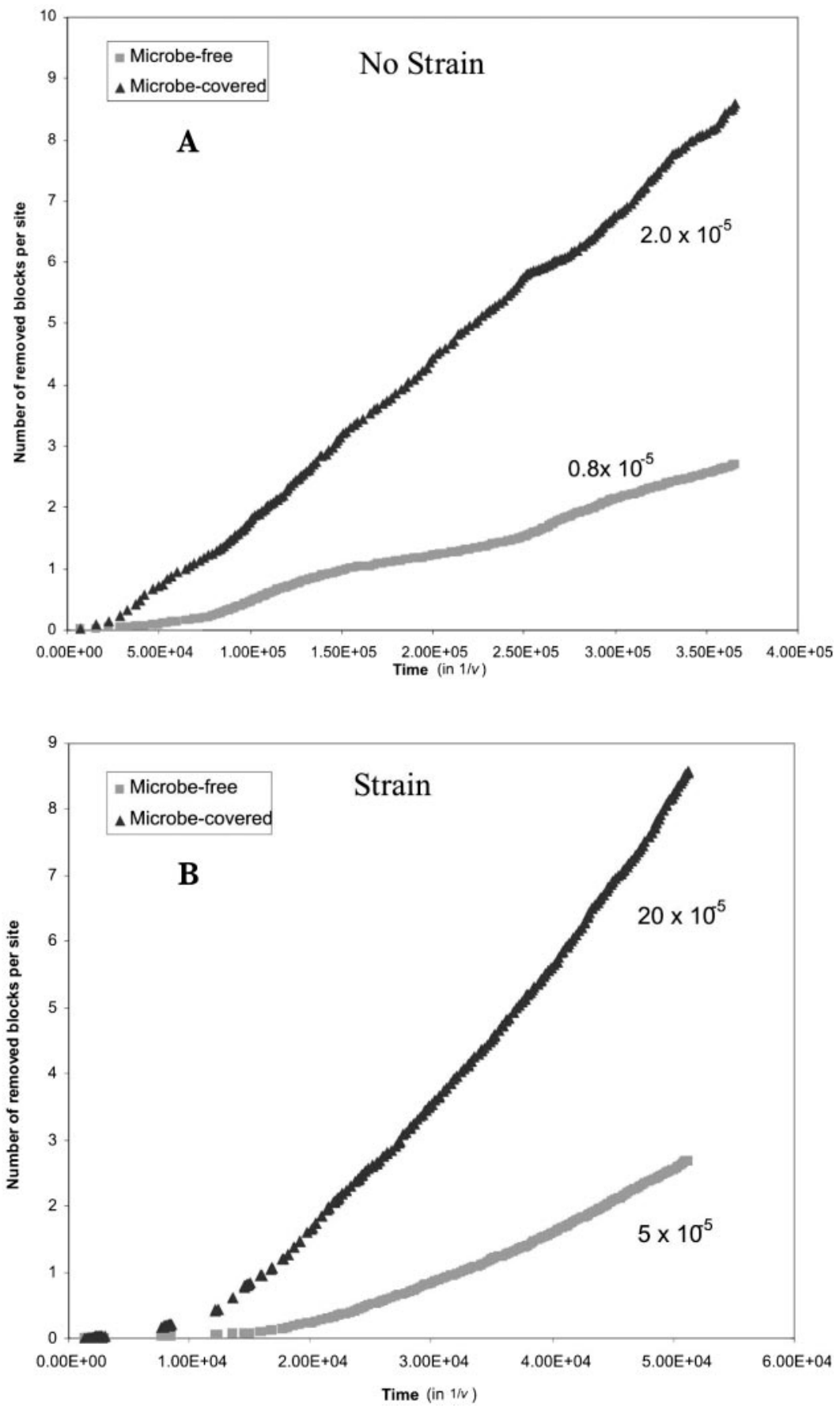

Fig. 11. (A) Plot showing the number of removed molecular blocks per site with time on a flat $\mathrm{AB}$ surface (case study represented in fig. 8); the rates (slopes) are $2.0 \times 10^{-5}$ and $0.8 \times 10^{-5}$ in the microbe-covered and microbe-free areas, respectively. Model parameters are given in figure 8 .

(B) Plot showing the number of removed molecular blocks per site with time on a flat AB surface with a screw dislocation (case study represented in fig. 10); the rates (slopes) are $20 \times 10^{-5}$ and $5 \times 10^{-5}$ in the microbe-covered and microbe-free areas, respectively. Model parameters are given in figure 8 . It is obvious that a strainfield increases the dissolution rate significantly. 


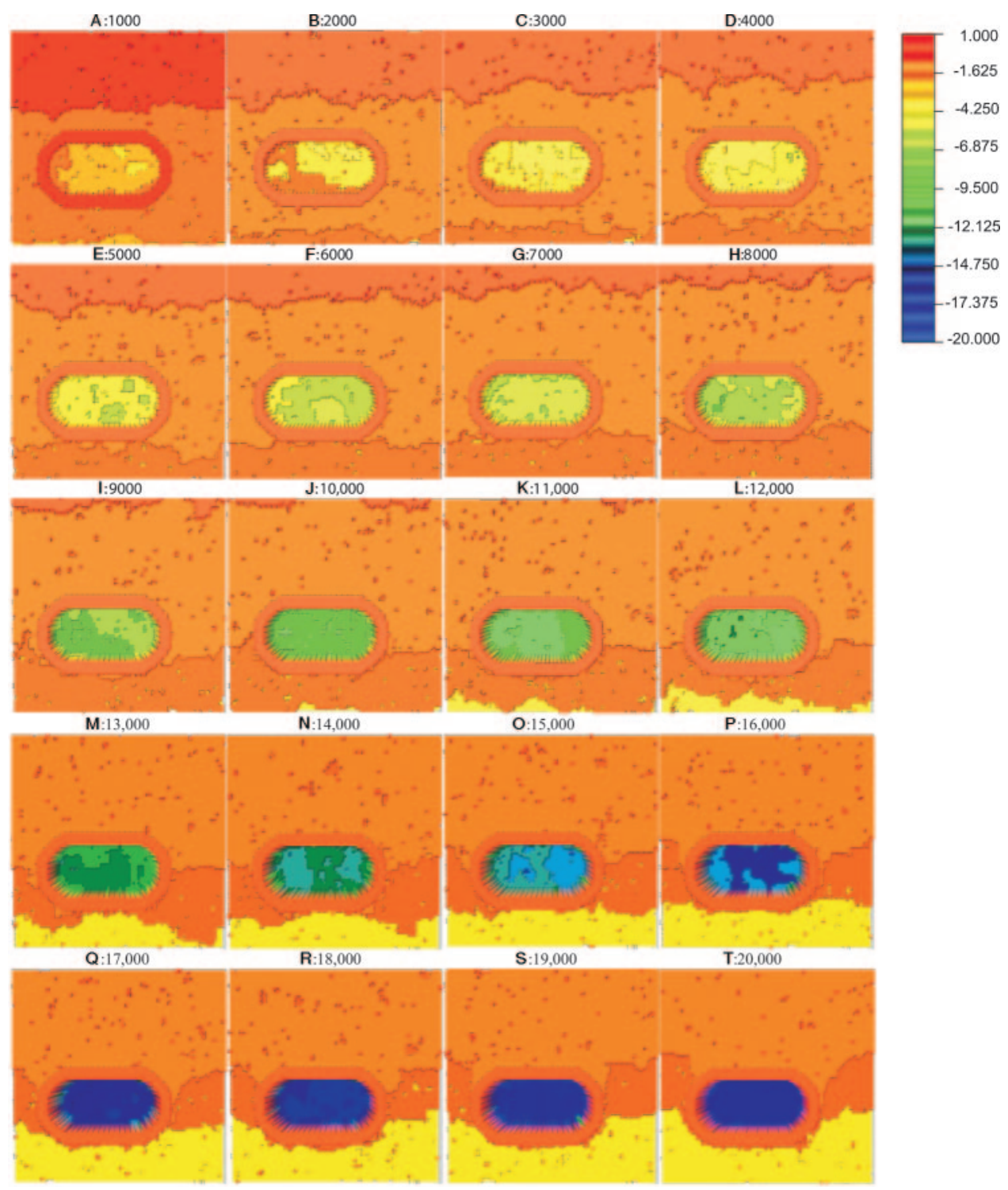

Fig. 12. Sequence of model results showing the surface topography after every 1,000 atomic blocks are removed, for a total of 20,000 blocks removed; the initial surface has two steps and has a rim of C-molecules around the bacteria covered area; entire model size: $80 \times 80$ blocks; area of increased undersaturation: $20 \times$ $30 ; \Delta \mu_{\mathrm{A}} / k T=\Delta \mu_{\mathrm{B}} / k T=-1.0$; saturation state of the outer area: $\Delta \mu_{\mathrm{A}} / k T=\Delta \mu_{\mathrm{B}} / k T=-0.2$; no surface diffusion is allowed; bond strength of A-B bonds, $\Phi_{\mathrm{AB}} / k T=2.49$, is constant for the entire model area.

graphically-oriented steps that travel across the surface. In the case of a solution that is undersaturated with respect to the solid, step movement will lower the crystal surface. All model parameters are given in the respective figure captions. As observed before in the other cases above, no new steps are generated at the etch pit created within the separate surface area that represents the microbe-mineral contact area. Steps that are present initially do travel across the surface. From previous calculations (Lasaga and Lüttge, 2004), we know that these steps would lower the surface continuously. In the 
case of bacteria presence, figures $12 \mathrm{~A}$ - T show that the section of the step that travels into the zone that is covered by C-molecules stops its movement completely. The two sections of the step that can bypass this red zone (for example, figs. 12H-T) slow down significantly. In longer runs, the following step could occasionally catch up with the first one, leading to step bunching. This effect was previously observed by Lasaga and Lüttge (2004a) for the abiotic case. Step bunching delays the further movement of the steps, and slows down the overall dissolution rate of the model surface.

SUMMARY OF MODEL RESULTS, DISCUSSION, AND POSSIBLE FUTURE DIRECTIONS

\section{Summary}

The results of our computer simulations can be summarized as follows: (i) the local decrease of saturation state over a crystal surface area and/or the increase of two-dimensional surface diffusion of A- and B-molecules lead-as expected-to the development of a large pit. (ii) This is true even in an atomically flat, undisturbed surface without the presence of a strain field. (iii) The same result can be generated if the bond strength between A and B molecules is reduced locally. (iv) Etch pit walls can be controlled and stabilized if the upper rim of the etch pit is inhibited by (organic) molecules, here simulated with C-molecules that have significantly higher bond energies. (v) This result was confirmed even if the pit develops into a shape with high kink-site density. (vi) The inhibition of the etch pit outskirt prevents the generation of stepwaves. (vii) A strain field within the simulated cell-surface contact area will cause the development of a well defined deep hole inside the already faster deepening bacterial pit. (viii) Crystallographically-oriented and crystallographically-controlled straight steps that travel into a simulated cell-surface contact area are broken. The section of the step that runs into the bacteria stops, and the sections to the right and left continue with reduced speed. After they have passed the bacterial site, they are likely to become curved.

\section{Discussion}

As already pointed out, the simulation used in the study above is quite simple and most likely an oversimplification. Therefore, we do not expect to extract any quantitative results with respect to reaction rates at this stage. However, our model calculations above have already generated interesting results that give some first insight into how bacterial attachment and interaction to crystal surfaces may impact dissolution kinetics mechanistically. An important result is that bacteria are able to form pits at the crystal surface by two simple mechanisms: (1) local decrease in free energy of the solution film in contact with the crystal surface; and (2) the weakening of certain bond strengths. A third mechanism may be the local increase or decrease in surface diffusion rate. However, results show that a biologically-controlled etch pit develops only if the molecular sites of the rim of the pit are strongly inhibited. Thus the biofilm may play a central role in localizing the pit itself. Both, the saturation state and the bond strength can be changed as a byproduct of "normal" bacterial activities, such as electron shuttling, proton pumping or production of $\mathrm{CO}_{2}$ during respiration. Although electron shuttling will change the bond strength of surface molecules, the latter two processes may change the $\mathrm{pH}$ of the solution. And while we have not yet studied the direct effects of $\mathrm{pH}$ change, the effects of changes in saturation state of the solution on crystal dissolution kinetics can be studied. The results are in good agreement with experimental results by Rosso and others (2003), Lüttge and Conrad (2004), Davis and others (2004).

Our simulation involving a strain field in the crystal surface structure is a realistic situation. Lüttge and Conrad (2004) have shown in their experiments with Shewanella oneidensis MR-1 on calcite cleavage surfaces that MR-1 cells preferentially attach to 
high-energy sites at the surface and prevent the abiotic opening of almost all etch pits that would occur without the microbes being present. To this end, our model calculations further predict the formation of a deep hole inside the microbial pit (see above). This prediction should be observable and tested experimentally using AFM and SEM techniques after the microbes have been removed from their locations of attachment (for example, Buss and others, 2003). If the existence of such holes cannot be verified, we will have to modify the model and locally incorporate transportcontrolled dissolution kinetics. This mechanism would also explain how the depth of a microbial pit can be controlled. This is an important question that we have not yet addressed. Experimental observations show that microbes do not entomb themselves in the crystal surface. In systematic measurements of microbial pit depths, Lüttge and Conrad (2004) showed that pits were never deeper than 150 nanometers. This result requires a kinetic mechanism that slows pit excavation at least to a rate that is equal to the surface-normal retreat of the surrounding crystal surface.

Our model calculations do not indicate any generation of steps at the outskirts of the microbial pits. Given that MR-1 attaches to high-energy sites such as the strain fields of dislocation outcrops, they occupy often the sites that are critical for the abiotic dissolution process. As discussed above, earlier model calculations and experimental studies have demonstrated that abiotically-formed pits generate stepwaves. By inhibiting the rim of biotically-formed etch pits, MR-1 prevents steps from being generated. Since this is an important mechanism in abiotic dissolution kinetics that even may control the overall rate of crystal dissolution in many cases it is important to study this effect in more detail. Of particular interest will be in situ AFM observations of the direct neighborhood of bacteria-occupied pits. If the model prediction is confirmed experimentally, and the formation of stepwaves at the pit wall is indeed successfully inhibited, we will have to face the possibility that microbial attachment can change dissolution rates dramatically. First experimental results by Lüttge and Conrad (2004) point in this direction. Despite these observations this result is still somewhat speculative but would have potentially large impact on weathering rates and other important geochemical processes.

Finally, our model results show that the steps and step velocities themselves can be influenced significantly by microbial attachment. This result is of significant importance to crystal dissolution kinetics. The fact that straight steps may be irreversibly transformed into rough, curved steps with high dislocation densities deserves further attention (Lüttge and Arvidson, unpublished). Here, we appreciate the fact that microbial attachment may not only influence step velocities but also may cause bunching and irreversible breakup of steps. The interplay of these changes in terms of the overall dissolution rate will be evaluated in a subsequent paper.

\section{Future Work}

We have made some suggestions for further experimental work that could test model predictions in our discussion above. A first step towards a more realistic computer model would be the use of a "real" crystal structure. This is already possible. Lüttge and Lasaga (unpublished) have used a full albite structure for simulations of abiotic dissolution. Such a model incorporating the full crystal structure requires both significantly more computer time and data such as bond strengths, surface free energies, surface diffusion rates, and adsorption energies. These data are often already available, or can be calculated in part by ab initio and other higher-level theoretical approaches (for example, Xiao and Lüttge, 2002). Such a parameterized Monte Carlo simulation is a very powerful approach that allows a stepwise improvement of the model towards significantly more realistic conditions and longer run durations while exploring larger and large sizes of a model system. Currently, hundred-thousands or even millions of molecules can be treated. In any case, it is desirable to employ 
significantly larger systems. Current calculations with barite (Fewless and others, unpublished) show that a system size of 100 by 100 unit cells is realistic if a high end personal computer with about $3 \mathrm{GHz} \mathrm{CPU}$ is used. This model size allows the incorporation of screw dislocations and even a combination of steps on the model (crystal) surface. The final goal is certainly a simulation size that allows the direct comparison with atomic force and vertical scanning interferometry observations during actual experiments.

Faster computers will further improve our ability to simulate larger systems and more realistic scenarios. A network of computers or a computer cluster, in contrast, does not seem very helpful. The way the current Monte Carlo code is programmed, it takes advantage of the variable time step and generates results very efficiently. To the best of our knowledge, compartmentalizing the grid for the use of a computer cluster does not gain an advantage.

\section{CONCLUSION}

Parameterized Monte Carlo simulations are a powerful tool to explore not only the abiotic reaction kinetics of crystal growth and dissolution but also the participation of microorganisms in this process. Fully parameterized Monte Carlo simulations should not require any "strategic" assumptions about reaction mechanisms, as has already been shown for the abiotic case. Even simple computer models using Monte Carlo techniques allow us to explore the changes in surface microtopography and process kinetics. Microorganisms predictably change the mechanism and rates of crystal dissolution when they attach to a mineral surface and change the saturation state or the bond strength between molecules through electron transfer. The modifications in reaction mechanisms and the resulting changes in overall reaction rates can be calculated and predicted by using computer simulations. Model predictions require experimental testing and verification. The number of required experiments, however, can be reduced by model predictions, because design and conditions of the experiments can be predetermined by the computer simulations.

\section{ACKNOWLEDGMENTS}

The authors wish to thank particularly R. S. Arvidson, P. G. Conrad, K. J. Davis, M. S. Beig, and M. D. Vinson for thoughtful discussion and reviews of earlier versions of this paper. Special thanks to referees J. D. Kubicki, and Y. Xiao for their insightful and critical comments and reviews, and last but not least K. J. Davis for providing excellent AFM and VSI images. The authors also acknowledge gratefully support for this study from the Department of Energy (grant\# DE- FG03-02ER63427), the Nanoscale Science and Engineering Initiative of the National Science Foundation under NSF Award Number EEC-0118007 (to A. Lüttge), and Molecular Instruments for the loan of a Pico Plus.

\section{REFERENCES}

Amend, J. P., and Helgeson, H. C., 2000, Calculation of the standard molal thermodynamic properties of aqueous biomolecules at elevated temperatures and pressures II. Unfolded proteins: Biophysical Chemistry, v. 84, p. 105-136.

Arnold, R. G., DeChristina, T. J., and Hoffman, M. R., 1988, Reductive dissolution of Fe(III) oxides by Pseudomonas sp. 200: Biotechnology and Bioengineering, v. 32, p. 1081-1096.

Arvidson, R. S., Ertan, I. E., Amonette, J. E., and Lüttge, A., 2003, Rates of calcite dissolution obtained by vertical scanning interferometry: Geochimica et Cosmochimica Acta, v. 67, p. 1623-1634.

Arvidson, R. S., Beig, M. S., and Lüttge, A., 2004a, Single-crystal plagioclase feldspar dissolution rates measured by vertical scanning interferometry: American Mineralogist, v. 89, p. 51-56.

Arvidson, R. S., Davis, K. J., Collier, M., Amonette, J. E., and Lüttge, A., 2004b, Etch pit morphology and magnesium inhibition of calcite dissolution, in Wanty, R. B., and Seal, R. R., editors: Proceedings of the $11^{\mathrm{th}}$ Symposium on Water-Rock Interactions, p. 721-725. 
Banfield, J. F., and Hamers, R. J., 1997, Processes at minerals and surfaces with relevance to microorganisms and prebiotic synthesis, in Banfield, J. F., and Nealson, K. H., editors, Geomicrobiology: interactions between microbes and minerals: Washington, D. C., Mineralogical Society of America, Reviews in Mineralogy, v. 35, p. 81-122.

Banfield, J. F., and Nealson, K. H., editors, 1997, Geomicrobiology: interactions between microbes and minerals: Washington, D. C., Mineralogical Society of America, Reviews in Mineralogy, v. 35, 448 p.

Barker, W. W., Welch, S. A., and Banfield, J. F., 1997, Biogeochemical weathering of silicate minerals, in Banfield, J. F., and Nealson, K. H., editors, Geomicrobiology: interactions between microbes and minerals: Washington, D. C., Mineralogical Society of America, Reviews in Mineralogy, v. 35, p. 391-428.

Barker, W. W., Welch, S. A., Chu, S., and Banfield, J. F., 1998, Experimental observations of the effects of bacteria on aluminosilicate weathering: American Mineralogist, v. 83, p. 1551-1563.

Berner, E. K., and Berner, R. A., 1995, Water, Air, and Geochemical Cycles: New York, Prentice Hall, 376 p.

Berner, R. A., 1992, Weathering, plants, and the long-term carbon cycle: Geochimica et Cosmochimica Acta, v. 56 , p. $3225-3231$

2003, The rise of trees and their effects on Paleozoic atmospheric $\mathrm{CO}_{2}$ and $\mathrm{O}_{2}$ : Comptes Rendus Geosciences, v. 335, p. 1173-1177.

Berner, R. A., and Westrich, J. T., 1985, Bioturbation and the early diagenesis of carbon and sulfur: American Journal of Science, v. 285, p. 193-206.

Blum, A. E., and Lasaga, A. C., 1987, Monte Carlo simulations of surface reaction rate laws, in Stumm, W., editor, Aquatic surface chemistry: Chemical processes at the particle-water interface: New York, J. Wiley, p. 255-292.

Borrok, D., and Fein, J. B., 2004, Distribution of protons and Cd between bacterial surfaces and dissolved humic substances determined through chemical equilibrium modeling: Geochimica et Cosmochimica Acta, v. 68, p. 3043-3052.

Borrok, D., Fein, J. B., and Kulpa, C. F., 2004, Proton and Cd adsorption onto natural bacterial consortia: testing universal adsorption behavior: Geochimica et Cosmochimica Acta, v. 68, p. 3231-3238.

Brantley, S. L., Liermann, L. J., Guynn, R. L., Anbar, A., Icopini, G. A., and Barling, J., 2004, Fe isotopic fractionation during mineral dissolution with and without bacteria: Geochimica et Cosmochimica Acta, v. 68 , p. $3189-3204$.

Buss, H. L., Brantley, S. L., and Liermann, L. J., 2003, Nondestructive methods for removal of bacteria from silicate surfaces: Geomicrobiology Journal, v. 20, p. 25-42.

Characklis, W. G., and Marshall, K. C., 1990, Biofilms: A basis for an interdisciplinary approach, in Characklis, W. G., and Marshall, K. C., editors, Biofilms: New York, J. Wiley and Sons, p. 3-16.

Davis, K. J., and Lüttge, A., 2005, Quantifying the potential role of microbial surface colonization in determining the mechanism and rate of carbonate dissolution: American Journal of Science, v. 305 , p. 727-751.

Davis, K. J., Conrad, P. G., and Lüttge, A., 2004, The mechanistic consequences of microbial surface colonization on carbonate mineral dissolution, in Wanty, R. B., and Seal, R. R., II, editors: Proceedings of the $11^{\text {th }}$ Symposium on Water-Rock Interactions, v. 2, Saratoga Springs, New York, June 27-July 2, 2004: London, United Kingdom, Taylor and Francis Group, p. 1101-1105.

Dove, P. M., De Yoreo, J. J., and Weiner, S., editors, 2003, Biomineralization: Washington, D. C., Mineralogical Society of America and Geochemical Society, Reviews in Mineralogy and Geochemistry, v. 54, 381 p.

Escher, A., and Characklis, W. G., 1990, Modeling the initial events in biofilm accumulation, in Characklis, W. G., and Marshall, K. C., editors, Biofilms: New York, J. Wiley and Sons, p. 445-486.

Fein, J. B., 2000, Quantifying the effects of bacteria on adsorption reactions in water-rock systems: Chemical Geology, v. 169, p. 265-280.

Frost, P. C., Maurice, P. A., and Fein, J. B., 2003, The effect of cadmium on fulvic acid adsorption to Bacillus subtilis: Chemical Geology, v. 200, p. 217-224.

Gilmer, G. H., 1976, Growth on imperfect crystal faces. I. Monte Carlo growth rates: Journal of Crystal Growth, v. 35, p. 15-28.

1977, Computer simulation of crystal growth: Journal of Crystal Growth, v. 42, p. 3-10

1980, Computer models of crystal growth: Science, v. 208, p. 355-363.

Helgeson, H. C., and Amend, J. P., 1994, Relative stabilities of biomolecules at high temperatures and pressures: Thermochimica Acta, v. 245, p. 89-119.

Hinsinger, P., Jaillard, B., and Duffery, J. E., 1992, Rapid weathering of trioctahedral mica by the roots of ryegrass: Soil Science Society of America Journal, v. 56, p. 977-982.

Jin, Q., and Bethke, C. M., 2003, A new rate law describing microbial respiration: Applied and Environmental Microbiology, v. 69, p. 2340-2348.

Kendall, T. A., and Hochella, M. F., Jr., 2003, Measurement and interpretation of molecular-level forces of interaction between the siderophore azotobactin and mineral surfaces: Geochimica et Cosmochimica Acta, v. 67, p. 3537-3546.

Larsen, I., Little, B., Nealson, K. H., Ray, R., Stone, A., and Tian, J., 1998, Manganite reduction by Shewanella putrefaciens MR-4: American Mineralogist, v. 83, p. 1564-1572.

Lasaga, A. C., 1990, Atomic treatment of mineral-water surface reactions, in Hochella, M. F., Jr., and White, A. F., editors, Mineral-water interface geochemistry: Washington, D. C., Mineralogical Society of America, Reviews in Mineralogy, v. 23, p. 17-85.

1998, Kinetic theory in earth sciences: Princeton Series in Geochemistry: Princeton, New Jersery, Princeton University Press, 811 p.

Lasaga, A. C., and Blum, A. E., 1986, Surface chemistry, etch pits and mineral-water reactions: Geochimica et Cosmochimica Acta, v. 50, p. 2363-2379.

Lasaga, A. C., and Lüttge, A., 2001, Variation of crystal dissolution rate based on a dissolution stepwave model: Science, v. 291, p. 2400-2404. 
2003, A model for crystal dissolution: European Journal of Mineralogy, v. 15, p. 603-615.

2004a, Kinetic justification of the solubility product: Application of a general kinetic dissolution model: Journal of Physical Chemistry, Part B, v. 109, p. 1635-1642.

2004b, Mineralogical approaches to fundamental crystal dissolution kinetics-Dissolution of an $\mathrm{A}_{3} \mathrm{~B}$ structure: European Journal of Mineralogy, v. 16, p. 713-729.

2004c, Mineralogical approaches to fundamental crystal dissolution kinetics: American Mineralogist, v. 89 , p. $527-540$.

Lee, S. K., and Stebbins, J. F., 1999, The degree of aluminum avoidance in aluminosilicate glasses: American Mineralogist, v. 84, p. 937-945.

Leyval, C., and Berthelin, J., 1991, Weathering of a mica by roots and rhizospheric microorganisms of pine: Soil Science Society of America Journal, v. 55, p. 1009-1016.

Little, B. J., Wagner P. A., and Lewandowski, Z., 1997a, Spatial relationships between bacteria and mineral surfaces, in Banfield, J. F., and Nealson, K. H., editors, Geomicrobiology: Interactions between and microbes and minerals: Washington, D. C., The Mineralogical Society of America, Reviews in Mineralogy, v. 35, p. 123-159.

Little, B. J., Wagner, P., Hart, K., Ray, R., Lavoie, D., Nealson, K. H., and Aguilar, C., 1997b, The role of metal-reducing bacteria in microbiologically influenced corrosion: Houston, Texas, Corrosion, National Association of Corrosion Engineers, v. 97, 215, 1.

Lovley, D. R., editor, 2000, Environmental microbe-metal interactions: Washington, D. C., ASM Press, 395 p.

Lovley, D. R., and Phillips, E. J., 1988, Novel mode of microbial energy metabolism: Organic carbon oxidation coupled to dissimilatory reduction of iron or manganese: Applied and Environmental Microbiology, v. 51, p. 683-689.

Lovley, D. R., Phillips, E. J., and Lonergan, D. J., 1991, Enzymatic versus nonenzymatic mechanisms for Fe(III) reduction in aquatic sediments: Environmental Science and Technology, v. 25, p. 1062-1067.

Lower, S. K., Tadanier, C. J., and Hochella, M. F., Jr., 2000, Measuring interfacial and adhesion forces between bacteria and mineral surfaces with biological force microscopy: Geochimica et Cosmochimica Acta, v. 64, p. 3133-3139.

Lower, S. K., Hochella, M. F., Jr., and Beveridge, T. J., 2001, Bacterial recognition of mineral surfaces: Nanoscale interactions between Shewanella and alpha-FeOOH: Science, v. 292, p. 1360-1363.

Lüttge, A., 2004, Connecting the molecular- with the macro-scale: An integrated approach towards a quantitative understanding of crystal dissolution, in Wanty, R. B., and Seal, R. R., editors, Proceedings of the $11^{\text {th }}$ Symposium on Water-Rock Interactions, v. 1: London, United Kingdom, Taylor and Francis Group, p. 841-844.

2004, Crystal Dissolution Kinetics studied by Vertical Scanning Interferometry (VSI) and Monte Carlo simulations: A Brief Review and Outlook, in Liu, X. Y., and De Yoreo, J. J., editors, Nanoscale structure and assembly at solid-fluid interfaces. Vol. I. Interfacial Structures versus Dynamics. Series on Nanoscience and Technologies: The Netherlands, Kluwer Academic Publishers, v. 1, 700 p.

- 2005, A kinetic model of etch pit coalescence and dissolution: American Mineralogist, v. 90, p. $1776-1783$.

Lüttge, A., and Conrad, P. G., 2004, Bacterial control of calcite dissolution kinetics: Applied and Environmental Microbiology, v. 70, p. 1627-1637.

Lüttge, A., Bolton, E. W., and Lasaga, A. C., 1999, An interferometric study of the dissolution kinetics of anorthite: The role of reactive surface area, in Canfield, D., and Boudreau, B., editors, Biogeochemical cycles and their evolution over geologic time. A special triple issue as a tribute to the career of Robert A. Berner: American Journal of Science, v. 299, p. 652-678.

Lüttge, A., Winkler, U., and Lasaga, A. C., 2003, Interferometric study of the dolomite dissolution: A new conceptual model for mineral dissolution: Geochimica et Cosmochimica Acta, v. 67, p. 1099-1116.

Myers, C. R., and Nealson, K. H., 1988, Bacterial manganese reduction and growth with manganese oxide as the sole electron acceptor: Science, v. 240, p. 1319-1321.

Nealson, K. H., and Little, B., 1997, Breathing manganese and iron: solid-state respiration: Advances in Applied Microbiology, v. 45, p. 213-239.

Nealson, K. H., and Stahl, D. A., 1997, Microorganisms and biogeochemical cycles: what can we learn from layered microbial communities? in Banfield, J. F., and Nealson, K. H., editors, Geomicrobiology: Interactions between microbes and minerals: Washington D. C., Mineralogical Society of America, Reviews in Mineralogy, v. 35, p. 1-34.

Nevin, K. P., and Lovley, D. R., 2000, Lack of production of electron-shuttling compounds or solubilization of $\mathrm{Fe}$ (III) during reduction of insoluble Fe(III) oxide by Geobacter metallireducens: Applied and Environmental Microbiology, v. 66, p. 2248-2251.

Newman, D. K., and Kolter, R., 2000, A role for excreted quinones in extracellular electron transfer: Nature, v. 405 , p. $94-97$.

Novitsky, J. A., 1981, Calcium-carbonate precipitation by marine-bacteria: Geomicrobiology, v. 2, p. 375-388.

Oelkers, E., 2001, General kinetic description of multioxide silicate mineral and glass dissolution: Geochimica et Cosmochimica Acta, v. 65, p. 3703-3720.

Patch, F. E., Davis, K. J., Conrad, P. G., and Lüttge, A., 2002, Microbial recognition of calcite surface microtopography: Towards an understanding of calcite dissolution rates in biological environments; abstract: GSA 2002 Fall meeting, Denver, CO., October 27-30, 2002.

Philpot, M., 2004, Atomic scale modeling of the solid-liquid interface, in Liu, X. Y., and De Yoreo, J. J., editors, Nanoscale structure and assembly at solid-fluid interfaces. Vol. I. Interfacial Structures versus Dynamics, Series on Nanoscience and Technologies: The Netherlands, Kluwer Academic Publisher, $700 \mathrm{p}$.

Rogers, J. R., Bennett, P. C., and Choi, W. J., 1998, Feldspar as a source of nutrients for microorganisms: American Mineralogist, v. 83, p. 1532-1540. 
Rosso, K. M., Zachara, J. M., Fredrickson, J. K., Gorby, Y. A., and Smith, S. C., 2003, Nonlocal bacterial electron transfer to hematite: Geochimica et Cosmochimica Acta, v. 67, p. 1081-1087.

Royer, D. L., Berner, R. A., and Beerling, D. J., 2001, Phanerozoic atmospheric $\mathrm{CO}_{2}$ change: evaluating geochemical and paleobiological approaches: Earth-Science Reviews, v. 54, p. 349-392.

Scott, C. C., Lüttge, A., and Athanasiou, K. A., 2004, Development and validation of vertical scanning interferometry as a novel method for acquiring chondrocyte geometry: Journal of Biomedical Materials Research, Part A, v. 72, p. 83-90.

Tang, R., Nancollas, G. H., and Orme, C. A., 2001, Mechanism of dissolution of sparingly soluble electrolytes: Journal of the American Chemical Society, v. 123, p. 5437-5443.

Tang, R., Orme, C. A., and Nancollas, G. H., 2003, A new understanding of demineralization: The dynamics of brushite dissolution: Journal of Physical Chemistry, Part B, v. 107, p. 10653-10657.

2004, Dissolution of crystallites: Surface energetic control and size effect: ChemPhysChem, v. 5, p. $688-696$.

Tossel, J. A., 1993, Theoretical studies of the speciation of Al in F-bearing aluminosilicate glasses: American Mineralogist, v. 78, p. 16-22.

Vinson, M. D., and Lüttge, A., 2005, Multiple Length Scale Kinetics: An integrated study of calcite dissolution rates and strontium inhibition: American Journal of Science, v. 305, p. 119-146.

Warren, L. A., 2004, A special issue dedicated to microbial geochemistry: Geochimica et Cosmochimica Acta, v. 68 , p. 3139.

Wehrli, B., 1989a, Monte Carlo simulations of surface morphologies during mineral dissolution: Journal of Colloid Interface Science, v. 132, p. 230-242.

1989b, Surface structure and mineral dissolution kinetics: A Monte Carlo study, in Miles, D. L., editor, Water-rock interaction: WRI-6: Proceedings of the 6th International Symposium on Water-Rock Interaction, Malvern, 3-8 August, 1989: Rotterdam, The Netherlands, A. A. Balkema, p. 751-753.

Westbroek, P., 1991, Life as a geological force: dynamics of the earth: New York, W.W. Norton and Co., 240 p.

Westrich, J. T., and Berner, R. A., 1984, The role of sedimentary organic matter in bacterial sulfate reduction: The G model tested: Limnology and Oceanography, v. 29, p. 236-249.

White, A. F., and Brantley, S. L., editors, 1995, Chemical weathering rates of silicate minerals: Washington, D. C., Mineralogical Society of America, Reviews in Mineralogy, v. 31, 583 p.

Xiao, Y., and Lüttge, A., 2002, Solvated $a b$ initio and density functional theory (DFT) modeling of mineral-fluid surface reactions: towards a better understanding of aluminosilicate dissolution mechanisms, (abstract): GSA 2002 Fall meeting, Denver, Colorado (October 27-30, 2002). 